\title{
Criocirugía en el tratamiento del cáncer de próstata
}

\author{
Pontones Moreno JL, Morera Martínez JF, Vera Donoso CD, Jiménez Cruz JF.
}

Servicio de Urología. Hospital Universitario La Fe. Valencia.

Actas Urol Esp. 2007:31(3):211-232

\begin{abstract}
RESUMEN
CRIOCIRUGÍA EN EL TRATAMIENTO DEL CÁNCER DE PRÓSTATA

En este trabajo se realiza una revisión sobre le estado actual de la criocirugía prostática en el tratamiento de los pacientes con cáncer de próstata. Los avances recientes acontecidos en la tecnología crioablativa permiten tratar eficazmente estos pacientes con una menor morbilidad. La utilización de ultrasonografia transrectal de alta resolución permite realizar la crioterapia prostática mediante la colocación percutánea transperineal de múltiples "crioagujas" de pequeño calibre (17-gauge). La extensión de la congelación puede ser controlada con precisión mediante dispositivos térmicos, la destrucción tisular prostática y en vecindad puede ser visualizada en tiempo real y el uso de calentadores uretrales evita el esfacelamiento uretral. Sin embargo, los resultados con los equipos de criocirugía de segunda y tercera generación tienen que ser validados mediante estudios aleatorizados y prospectivos, ya que hasta la actualidad sólo disponemos de datos basados en estudios retrospectivos, que son muy heterogéneos. La capacidad del antígeno prostático específico para predecir la evolución a largo plazo tras la criocirugia en los pacientes con cáncer prostático localizado no es bien conocida puesto que la experiencia con esta modalidad terapéuticas es todavía limitada; aunque parece que un valor de PSA $<0,5 \mathrm{ng} / \mathrm{ml}$ a los 6 meses del tratamiento indicaria una alta probabilidad ( $>95 \%$ ) de biopsia negativa post-tratamiento. La criocirugia podría ser útil también en el tratamiento de la recurrencia local en pacientes tratados mediante prostatectomía radical o radioterapia. Debemos tener presente la posibilidad de complicaciones (incontinencia, impotencia, fistula uretrorectal, u obstrucción infravesical). El perfil favorable de efectos adversos y los resultados preliminares oncológicos y funcionales sugieren que la criocirugía tendrá indicación en el tratamiento mínimamente invasivo de pacientes seleccionados con cáncer de próstata.
\end{abstract}

Palabras clave: Criocirugía. Cáncer de próstata.

\section{ABSTRACT}

\section{CRYOSURGERY IN THE MANAGEMENT OF PROSTATE CANCER}

This article reviews the current status of the prostatic cryosurgery in the management of patients with prostate cancer. Recent advances in cryoablative technology have allowed to treat these patients successfully with decreased morbidity. Using transrectal high-resolution ultrasound imaging, prostate cryotherapy is delivered with multiple ultrathin (17-gauge) cryo-needles, via percutaneous transperineal approach. The extent of freezing can be precisely controlled and monitored with thermic devices, tissue destruction is monitored with real-time visualization of the prostate and surrounding structures, and urethral warming is used to avoid urethral sloughing. However, the results with the second and third-generation cryosurgical equipment will have to be confirmed by means of prospective and randomized trials, because up to now we only have data based on retrospective analyses, which are very heterogeneous. The ability of prostate-specific antigen (PSA) to predict long-term outcome after cryotherapy for localized prostate cancer is not well known because experience with this treatment modality is still limited; however, it seems that a PSA value of $0.5 \mathrm{ng} / \mathrm{ml}$ or less after 6 months or longer after cryotherapy would be associated with a high probability (greater than 95\%) of negative post-treatment biopsy. Cryosurgery could also be an option of treatment for men with recurrent local disease who have undergone radiotherapy or radical prostatectomy. We have to keep in mind possible complications (incontinence, impotency, urethrorectal fistula or bladder outlet obstruction. The favorable side effect profile and preliminary oncologic and funtional results could suggest that cryosurgery will have a role in the minimally invasive management of selected patients with prostate cancer.

Keywords: Cryosurgery. Prostate cancer. 
$\mathrm{E}$ tratamiento idóneo del carcinoma de próstata localizado es un problema que siempre genera cierta polémica. En la actualidad, la mayoría de los urólogos consideran la prostatectomía radical, en sus diferentes variedades técnicas (retropúbica, perineal o laparoscópica) como el tratamiento de elección en pacientes con una buena expectativa vital. Por su parte, los radioterapeutas consideran las distintas técnicas de radioterapia radical como el tratamiento idóneo para el cáncer de próstata localizado. En los últimos años, se ha añadido a esta polémica, la posibilidad de aplicar otras fuentes de energía capaces de destruir las células neoplásicas.

El objetivo de los procedimientos de ablación tisular basados en la aplicación de energía es conseguir la destrucción de una determinada área de tejido con el margen de seguridad necesario de tejido sano circundante, que de otro modo precisaría un tratamiento quirúrgico, y evitar así la agresividad de este. Las modalidades de ablación actualmente disponibles varían en función del tipo de energía utilizado, el mecanismo de necrosis celular, y el mecanismo productor de energia.

La situación anatómica de la próstata la convierte en un órgano accesible por diferentes vías (transuretral, transperineal, transrectal, suprapúbica), por lo que siempre ha constituido un órgano atractivo para aplicar lo que genéricamente podemos denominar tratamientos ablativos mínimamente invasivos o cirugía mínimamente invasiva. Se trata de procedimientos que tienen como finalidad conseguir la erradicación de la enfermedad con la menor morbilidad posible y permitiendo la conservación del órgano en cuestión. La mayoría son técnicas que aún están en fase de desarrollo, con escasa implantación y pendientes de establecer su verdadera eficacia. Entre ellas encontramos: High-intensity focused ultrasound (HIFU), ablación por radiofrecuencia intersticial (RITA), termoterapia por microondas, $\mathrm{si}$ bien la más estudiada y difundida es la criocirugia (CRA).

La principal limitación para el empleo de estas técnicas es la imposibilidad, actualmente existente, de conocer con exactitud la localización y el volumen del tumor. Posiblemente, con el desarrollo de futuras técnicas de imagen que ayuden a clarificar estos aspectos de la enfermedad, estas nuevas modalidades terapéuticas tendrán una mayor difusión para tratar pacientes con cáncer de próstata localizado.

\section{ASPECTOS HISTÓRICOS}

La aplicación de la criocirugía en la patología prostática se remonta a la década de los años $60^{1,2}$, cuando se diseñaron aparatos que permitían la aplicación del frío a la glándula prostática y tratar pacientes con hiperplasia prostática. La congelación se conseguía mediante la introducción transuretral de una criosonda de nitrógeno líquido, que era reposicionada varias veces para conseguir un mayor volumen de tejido congelado, $\mathrm{y}$ el control del proceso se hacia mediante tacto rectal. En la década de los 70 se intento mejorar el procedimiento colocando las criosondas mediante un abordaje transperineal abierto para exponer la glándula prostática ${ }^{3}$.

Los resultados iniciales de la criocirugía en pacientes con cáncer de próstata fueron pobres. La elevada morbilidad producida obligó al abandono de esta técnica, pues presentaba un elevado índice de complicaciones locales: fístulas uretrorectales y uretrocutáneas, esclerosis de cuello vesical, esfacelamiento uretral, incontinencia urinaria, y una disfunción eréctil prácticamente generalizada. Tampoco demostró un adecuado control local del tumor, ya que la tasa de recurrencia local superaba el $65 \%{ }^{4}$. Además, en esta primera etapa no existía una tecnología adecuada para monitorizar el proceso de congelación con la mejor precisión.

No obstante, desde sus inicios, la CRA prostática demuestra algunos beneficios con respecto a otros tratamientos empleados en el cáncer de próstata: respeta las estructuras vecinas, la pérdida hemática es mínima y representa una alternativa en aquellos pacientes no idóneos para cirugía o radioterapia.

En la década de los 80, la introducción de los ultrasonidos como medio de diagnóstico por imagen supone una revolución en el campo de la Urología y repercute positivamente en las posibilidades terapéuticas de la criocirugía prostática. La ecografia transrectal permite, por una parte, observar el proceso de congelación tisular como una imagen anular, perfectamente delimitada, hipere- 
cogénica y con sombra acústica; por otra parte, es capaz de identificar las criosondas, ayudando a controlar adecuadamente su colocación. Además, el diseño de sistemas que permiten la colocación de múltiples criosondas (que consiguen una distribución más uniforme de la temperatura) y la utilización de sondas de calentamiento uretral, mejoraron notablemente la eficacia del procedimiento ${ }^{5,6}$.

$\mathrm{El}$ avance tecnológico acontecido en la última década ha posibilitado el desarrollo de instrumentos de gran precisión para producir una congelación tisular controlada y eficaz (tasa de descenso de PSA a menos de $0,5 \mathrm{ng} / \mathrm{ml}$ hasta en un $84 \%$ de pacientes), con una notable disminución de la morbilidad ocasionada por los primeros aparatos empleados en la CRA prostática (tasa de fístula rectouretral menor del $1 \%$ y de incontinencia alrededor de $5 \%)^{1,7}$; y que además, son instrumentos familiares para el urólogo, por lo que el adiestramiento no es complicado. El empleo de gases que producen una rápida congelación (argón), la posibilidad de aplicar simultáneamente gases para conseguir calentamiento tisular, el control en tiempo real, mediante ecografía y sensores térmicos, del crecimiento del área congelada; y por último, la monitorización computerizada de todas las fases del procedimiento crioterápico, son algunos de los aspectos que convierten a la CRA en una atractiva posibilidad de "tratamiento mínimamente invasivo” del cáncer de próstata localizado.

Seguramente en los próximos años dispondremos de técnicas de diagnóstico por imagen que identifiquen la localización exacta del área neoplásica y, por tanto, permitan concentrar la energía en dicha zona consiguiendo una máxima eficacia con la mínima morbilidad.

\section{FUNDAMENTOS BIOLÓGICOS DE LA CRIOCIRUGÍA}

La criocirugía prostática consiste en la congelación "in situ" y controlada del tejido prostático con la finalidad de producir la ablación de una parte o de toda la glándula prostática para conseguir la erradicación de la enfermedad conservando, al mismo tiempo, la integridad anatómica de las estructuras vecinas.

\section{Mecanismos implicados en la lesión tisular}

Antes de describir los detalles de la técnica de la crioablación prostática es importante conocer los mecanismos por los que se produce la lesión tisular y la evolución de las lesiones originadas tras la aplicación del frío. Las técnicas actuales consiguen la crioablación mediante la modificación de la temperatura aplicada para inducir ciclos sucesivos de congelación y descongelación, en cada uno de los cuales ocurren determinadas alteraciones celulares. (Tabla 1).

\section{Tabla 1}

Mecanismos de acción de la crioablación

1. Desnaturalización proteica secundaria a deshidratación celular

2. Ruptura directa de membrana celular inducida por cristalización intracelular

3. Éstasis vascular

4. Lesión endotelial vascular secundaria a agregación plaquetar e isquemia

5. Inducción de la apoptosis

El frío, a temperaturas de congelación, puede causar un daño irreparable de la estructura tisular y celular. La respuesta tisular al frío varía según la intensidad del daño producido, y así, cuando el daño criogénico es leve (bajas temperaturas de congelación) solamente se produce una reacción inflamatoria, mientras que si el daño criogénico es severo (altas temperaturas de congelación) se consigue la destrucción tisular, objetivo que persigue la criocirugia. Es necesario conseguir temperaturas de -40 ó -50 grados centígrados para que se produzca la muerte celular ${ }^{8}$.

El daño tisular ocasionado por el frío parece ser un proceso multifactorial ${ }^{6-10}$. La temperatura de congelación máxima obtenida por la criocirugía produce un daño celular directo derivado de la cristalización del líquido extracelular que ocurre a temperaturas inferiores a $0^{\circ} \mathrm{C}$. Este fenómeno provoca un aumento de la presión osmótica en el espacio extracelular con la consiguiente salida de líquido intracelular para equilibrar el exceso de presión. La deshidratación celular, que ocurre a temperaturas de 0 a $-20^{\circ} \mathrm{C}$, resulta en una lesión de la membrana celular y de la estructura enzimática intracelular, que sí dura el tiempo 
suficiente acaba con la muerte celular aunque no se alcancen temperaturas excesivamente bajas. Cuando se alcanzan temperaturas inferiores a $40^{\circ} \mathrm{C}$, y si el proceso de congelación es rápido, a todo lo anterior se une un fenómeno letal de cristalización intracelular.

Otro mecanismo esencial implicado en este proceso es el daño vascular ${ }^{8-12}$. El proceso de enfriamiento produce vasoconstricción a nivel de la microcirculación disminuyendo el aporte de oxígeno y nutrientes a las células, a la vez que provoca lesiones directas en las células endoteliales. Durante el ciclo de descongelación se produce una vasodilatación y aumento de flujo sanguíneo que, a nivel de los capilares ya dañados por la congelación previa, se traducen en la extravasación de líquido y formación de edema, una activación plaquetar e inicio de un proceso de coagulación intravascular con formación de microtrombos. Todos estos acontecimientos provocan una oclusión vascular e intensa respuesta inflamatoria (con activación de polimorfo nucleares y formación de radicales libres), creando una zona isquémica que finalmente conducen a una necrosis celular, si bien esta necrosis no alcanza la periferia del área de tejido previamente congelado.

Otros procesos que ocurren a nivel molecular, menos estudiados, también parecen intervenir en las lesiones inducidas por la congelación. En estudios "in vitro" se observa que la hipotermia subletal induce la expresión de determinados genes que regulan la producción de proteínas que intervienen en el crecimiento celular y la apoptosis: factor de crecimiento endotelio-vascular (VEGF) y fibroblástico (B-FGF), interleuquina-8 (IL-8) y otras citoquinas. Estos mecanismos explicarían la destrucción tisular que ocurre en la periferia del área de congelación, donde no se alcanzan temperaturas tan bajas como en la zona central (de necrosis), y que ocurre minutos o horas más $\operatorname{tarde}^{13,14}$. Se ha comprobado la aparición de apoptosis en rangos de temperatura de $6^{\circ} \mathrm{C} \mathrm{a}-10^{\circ} \mathrm{C}$; por lo cual, en la periferia de la zona de congelación, donde las temperaturas oscilan entre $0^{\circ}$ y $-20^{\circ}$, la aparición de fenómenos apoptóticos incrementa el volumen de tejido necrosado ${ }^{15}$.

Aunque algunos estudios sugieren la participación de una respuesta inmunitaria en las lesiones ocasionadas por la congelación, éste aspecto no ha sido completamente aclarado $^{10}$.

\section{Factores condicionantes de la ablación tisular}

Está demostrado que el tejido próximo a la criosonda se enfría más rápidamente y alcanza las temperaturas mínimas, con lo cual la probabilidad de destrucción celular es mayor que en el tejido periférico, donde el enfriamiento es más lento y no alcanza temperaturas tan bajas $^{8}$. Existen una serie de factores físicos que determinan el nivel de lesión tisular (Tabla 2).

\section{Tabla 2}

Factores condicionantes de los efectos de la crioablación

1. Velocidad de enfriamiento

2. Temperatura tisular mínima

3. Duración del periodo de congelación

4. Velocidad de descongelación

5. Número de ciclos de congelación-descongelación

6. Intervalo de tiempo entre ciclos de congelación-descongelación

Velocidad de enfriamiento. Experimentalmente, en estudios in vitro, se ha comprobado que el enfriamiento rápido es más destructivo ya que provoca formación de hielo intracelular, que es letal ${ }^{16,17}$. Existe una gran variabilidad en el rango de velocidades de enfriamiento para conseguir la formación de hielo intracelular dependiendo de la extirpe celular: en el hepatocito la formación de hielo intracelular requiere una velocidad de enfriamiento de $22^{\circ} \mathrm{C} / \mathrm{min}^{18}$, mientras que las células del cáncer de próstata precisan una velocidad de $25^{\circ} \mathrm{C} / \mathrm{min}^{17}$ y las del cáncer de mama de $3^{\circ} \mathrm{C}^{19}$.

En consecuencia, en criocirugía, la velocidad de enfriamiento debe ser siempre tan alta como sea posible para producir la formación de hielo intracelular letal. La máxima velocidad de enfriamiento se consigue en la zona más próxima a la implantación de la criosonda ${ }^{8,20}$, donde se pueden alcanzar velocidades de enfriamiento de $50^{\circ} \mathrm{C} / \mathrm{min}$ o superiores, mientras que la velocidad desciende progresivamente al alejarse del punto de implantación de la criosonda, siendo el enfriamiento lento (subletal) en los limites externos del área de tejido sometido a congelación. 
Temperatura tisular.- La intensidad de los fenómenos que producen la necrosis celular durante la criocirugía varían en función de la temperatura final (minima) alcanzada ${ }^{8,10,16,21}$. La cristalización de los solutos del espacio extracelular y la deshidratación celular subsiguiente, así como la formación de hielo intracelular se incrementan con la disminución de la temperatura. En un experimento realizado sobre líneas celulares de cáncer renal ${ }^{22}$, se pudo observar que al congelar las células durante 60 minutos a $-10^{\circ} \mathrm{C}$ sobrevivía un $96 \%$ de las células, mientras que si se alcanzaba una temperatura mínima de $-20^{\circ} \mathrm{C}$ sólo lo hacía un $15 \%$. Las células difieren en su susceptibilidad a las lesiones de enfriamiento en función de su extirpe, encontrándose el rango crítico de temperaturas letales entre $-5^{\circ} \mathrm{C}$ y $-50^{\circ} \mathrm{C}$, siendo las células neoplásicas más resistentes que las células normales a las lesiones por enfriamiento.

En la criocirugía del cáncer es fundamental, lógicamente, alcanzar una temperatura final capaz de producir la destrucción de todas la células neoplásicas. Mediante experimentos in vitro e in vivo se ha podido establecer que temperaturas de $-40^{\circ} \mathrm{C}$ a $-50^{\circ} \mathrm{C}$ son críticas para producir la necrosis celular mediante ciclos únicos de congelación-descongelación ${ }^{8,10,17}$.

La determinación de la temperatura tisular es uno de los parámetros más útiles para monitorizar los procedimientos de crioablación.

Duración del periodo de congelación. Una vez que se alcaza la temperatura mínima idónea para conseguir la congelación tisular es posible conseguir un mayor daño celular prolongando el periodo de congelación ${ }^{8,10,15,23}$. No se conoce con exactitud cual es el tiempo optimo durante el cual se debe mantener la congelación y posiblemente se trate de un parámetro dependiente del tipo celular o tisular. Al prolongar el tiempo de congelación se favorece la deshidratación celular, el daño vascular y la aparición de fenómenos de recristalización intracelular que incrementan el daño celular y disminuyen las posibilidades de supervivencia tisular. La influencia del tiempo de congelación es evidente en un determinado rango de temperatura, pero es un factor irrelevante cuando se alcanzan temperaturas finales de $50^{\circ} \mathrm{C}$.
Velocidad de descongelación. En los procedimientos de crioablación a la fase de congelación sucede siempre una de descongelación que incrementa el daño tisular ya producido. La velocidad a la que ocurre esta fase influye en la severidad del daño producido ${ }^{8,10,16}$. Si la descongelación se produce con rapidez, el grado de deshidratación celular y el crecimiento de los cristales de hielo es menor, con lo que aumentan las posibilidades de supervivencia de las células. Algunos experimentos demuestran como una fase de descongelación lenta es más lesiva que una congelación rápida ${ }^{11,15}$.

Repetición del ciclo congelación-descongelación. Después de un proceso de congelación, las células son mucho más vulnerables, por lo que la aplicación de ciclos sucesivos de congelación-descongelación provoca un daño tisular mayor que la aplicación de un único ciclo $8,10,15,17,24$. La rotura de membrana celular y las lesiones del sistema enzimático ocasionadas por el primer ciclo aumenta la conductividad térmica del tejido incrementando la sensibilidad del mismo a los efectos de un nuevo proceso de congelación. En el segundo ciclo se produce una congelación más rápida del tejido previamente lesionado produciendo la necrosis de las células que no han sido completamente destruidas con el primer ciclo. Además aumenta el volumen de los cristales de hielo intracelular que adquieren, un mayor poder destructivo.

Con el segundo ciclo se consigue un incremento de destrucción celular de hasta un $80 \%$ del volumen previamente congelado ${ }^{15,25}$. Los efectos del segundo ciclo de congelación-descongelación son mejor observados en rango de temperatura subletal $\left(-20^{\circ}\right.$ a $\left.-30^{\circ}\right)$ ya que como hemos comentado antes temperaturas más bajas (-50 $\mathrm{C}$ o más bajas) producen la destrucción celular completa en un solo ciclo.

Con ello se consigue, por una parte aumentar el volumen de tejido destruido y por otra extender el daño celular hasta las proximidades del límite periférico del área de congelación, donde el grado de destrucción fue menor.

Intervalo entre ciclos. También se ha observado que al prolongar el intervalo entre los dos ciclos de congelación se eleva el poder destructivo del segundo ciclo ${ }^{8,10,15}$. Si se mantiene más 
tiempo el grado de hipotermia alcanzado tras la fase de descongelación del primer ciclo se incrementa el daño producido a nivel de la microcirculación y las alteraciones osmóticas, y se favorece al mismo tiempo el crecimiento del hielo intracelular.

Criobiologia del adenocarcinoma prostático

En experimentos in vitro con cultivos de células de cáncer de próstata, tanto en tejidos animales como humanos, se observa como temperaturas de -20 a $-40^{\circ} \mathrm{C}$ (o incluso más bajas), en función de la velocidad de congelación, son necesarias para conseguir la destrucción completa de las células de cáncer de próstata y que dos ciclos de congelación-descongelación tienen mayor capacidad destructiva que un ciclo único ${ }^{10,17}$. Estos dos aspectos son determinantes para conseguir una mayor eficacia terapéutica y condicionan la técnica de la criocirugía prostática en cuanto a disminución de los niveles de PSA y tasa de biopsias negativas después del tratamiento 26,27 .

En estudios in vivo, realizados recientemente sobre tejido prostático humano ${ }^{28}$, se encontró que la temperatura mínima necesaria para producir daño celular era de $-29,6^{\circ} \mathrm{C}$ si se aplicaban dos ciclos de congelación y de $-47,6^{\circ} \mathrm{C}$ al aplicar un ciclo. Sin embargo, la temperatura mínima capaz de producir necrosis celular era de $-41,4^{\circ} \mathrm{C}$ con dos ciclos de congelación y de $-61,7^{\circ} \mathrm{C}$ con un solo ciclo. También se observa que el volumen medio de tejido prostático incluido en la zona de necrosis es significativamente mayor con dos ciclos de congelación ( $13 \%$ vs $4 \%$ ).

La lesión criogénica del tejido prostático tiene una forma esférica (es denominada esfera helada) y presenta dos zonas térmicas claramente diferenciadas ${ }^{17,28}$ : una zona central (próxima a la zona de implantación de la criosonda) con temperaturas de -20 a $-40^{\circ} \mathrm{C}$, en la que acontece una necrosis coagulativa que provoca la destrucción celular completa y uniforme; y alrededor de esta, una zona periférica con temperaturas que pueden llegar a $0^{\circ} \mathrm{C}$, en la que pueden sobrevivir células con capacidad proliferativa que tendrían la posibilidad de originar una recurrencia tumoral. Además ambas zonas pueden ser distinguidas ecográficamente, pues la zona periférica es mar- cadamente hiperecogénica.

Por lo tanto, no existe una correspondencia exacta entre el área de congelación observada en la ecografía transrectal y el volumen real de tejido necrosado, por lo que para asegurar la erradicación completa del tejido diana es necesario aumentar el área de congelación más allá de los limites ecográficos del tejido a tratar $10,15,17,27,28$. Para asegurar la radicalidad oncológica, la esfera de hielo puede abarcar lateralmente hasta 2-4 $\mathrm{mm}$ del tejido periprostático, la muscularís propia del recto posteriormente y sobrepasar el ápex prostático. Cuando existe extensión extracapsular del tumor los limites laterales de la esfera de hielo pueden ser ampliados.

En consecuencia, se entiende que los ultrasonidos tienen limitaciones para conseguir una monitorización exacta de la extensión de la lesión criogénica; y en la crioablación del carcinoma prostático es fundamental un control exacto de la temperatura para asegurar la eliminación de las células neoplásicas y prevenir las complicaciones ${ }^{1,28,29}$. Por ello se utilizan termosensores introducidos junto a las criosondas, cuya información es pocesada mediante modelos matemáticos para poder tener un control más exacto de las temperatura alcanzadas en las diferentes áreas (isotermas) de la zona tratada $20,30,31$. Este aspecto es de particular importancia en los pacientes con gran volumen tumoral, estadios localmente avanzados y en las recurrencias locales postprostatectomía o postradioterapia.

En el tratamiento del cáncer de próstata es esencial la aplicación de un segundo ciclo de congelación, ya que este puede desplazar la isoterma de temperatura letal a $-20^{\circ} \mathrm{C}$, y así extender la zona de congelación hasta los límites de la glándula prostática con mínimo riesgo de lesión de los órganos adyacentes ${ }^{15,28}$.

\section{ASPECTOS TÉCNICOS}

Como se ha comentado anteriormente, la técnica de de la criocirugía prostática y la tecnología aplicada a la misma han sufrido notables cambios desde sus inicios en la década de 1960. Hoy la técnica de la crioablación prostática está perfectamente definida en cuanto a sus fundamentos biológicos y tecnológicos ${ }^{5,6,30,31}$. (Tabla 3). Los principios fundamentales son: 
Tabla 3

Aspectos fundamentales de la técnica de crioablación

1. Distribución homogénea de las criosondas. Control ultrasonográfico

2. Temperatura mínima de congelación entre -20 a $-40^{\circ} \mathrm{C}$

3. Control estricto mediante el uso de sensores térmicos

4. Repetición del ciclo congelación-descongelación

5. Uso de calentador uretral

6. Empleo de hormonoterapia neoadyuvante para disminuir tamaño prostático

1. Congelación rápida.

2. Descongelación lenta.

3. Repetición del ciclo congelado-descongelado.

En la actualidad, los aparatos de crioterapia existentes en el mercado constan de tres componentes básicos:

1. Sistema de criosondas.

2. Sonda transrectal de ultrasonidos.

3. Sonda de calentamiento uretral.

Los aparatos actuales de criocirugía prostática incorporan un sistema de criosondas múltiples (los primeros utilizaban una única sonda), que se colocan mediante acceso percútanlo transperineal bajo control ecográfico. La posibilidad de colocar múltiples sondas que pueden ser enfriadas simultáneamente ofrece grandes ventajas: distribución uniforme de la temperatura mínima necesaria, reproducir con mayor exactitud la topografía de la zona a tratar y disminuir el riesgo de lesiones colaterales (Fig. 1).

Las criosondas poseen un sistema de dobleluz, una (luz central) es utilizada para adminis-

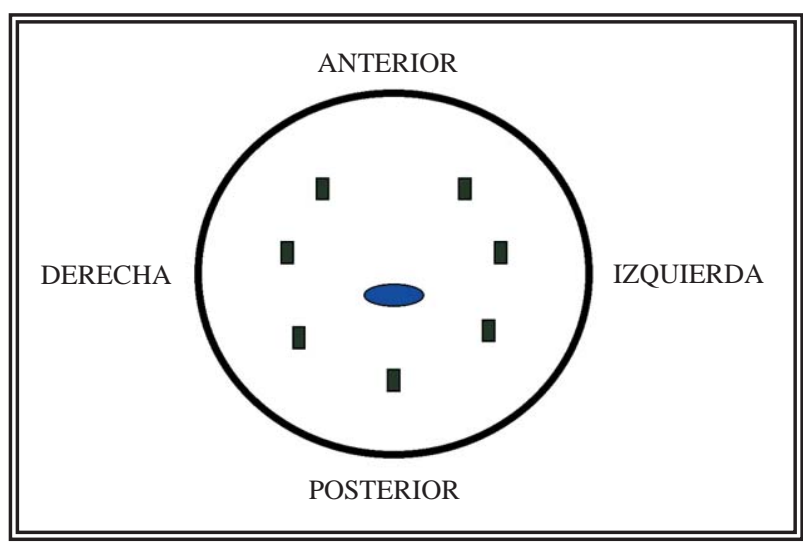

FIGURA 1. Esquema de disposición de las criosondas. trar el agente criógeno y la otra (luz exterior) permite la salida del gas conforme se produce su evaporación.

La eficacia de la crionecrosis está influenciada por las características físicas de la criosonda: su diámetro y su nadir de temperatura. El calibre de las sondas condiciona la velocidad de congelación y determina el volumen de tejido congelado (esfera de hielo) ${ }^{6,15,32-34}$. Cuanto mayor es el calibre, mayor es el diámetro que alcanza la esfera de hielo originada por la sonda. Los calibres de las sondas utilizadas en criocirugía prostática varían entre 1,4 mm (crioagujas) y $3 \mathrm{~mm}$, compensándose la diferencia de tamaño de la esfera de hielo originada por las sondas más pequeñas colocando un mayor número de ellas. La utilización de crioagujas tiene la ventaja de conseguir una distribución mucho más homogénea de la temperatura de ablación en el tejido diana. Los aparatos de criocirugía de tercera y cuarta generación permiten el enfriamiento de múltiples crioagujas de forma simultánea.

Disponemos de varios agentes criogénicos utilizables en criocirugía. Las diferencias entre ellos están marcadas por su punto de ebullición específico ( $\mathrm{pEE}$ ), el cual determina el nadir de temperatura que se puede alcanzar con la criosonda. Los dos agentes criogénicos más utilizados son Argón líquido ( $\mathrm{pEE}$ de $-186^{\circ} \mathrm{C}$ ) y Nitrógeno líquido ( $\mathrm{pEE}$ de $\left.-196{ }^{\circ} \mathrm{C}\right)$ que ofrecen resultados clínicos equiparables. El Argón presenta algunas ventajas: puede ser aplicado a través de sondas de mínimo calibre $(1,4 \mathrm{~mm})$, permite mayor velocidad de enfriamiento y, al ser un gas inerte, es más fácil de manipular e introducir en la sonda. Por el contrario, el Nitrógeno requiere sondas de más calibre (> $3,5 \mathrm{~mm}$ ) y es un gas inestable lo que hace más dificil su almacenamiento, el control de su circulación ambiental y su insuflacción ${ }^{6,30}$.

La misma sonda utilizada para introducir el agente criógeno permite la introducción de Helio, gas que es insuflado inmediatamente después de detener la insuflación del Argón y así, se evita la progresión de la congelación tisular y se induce la descongelación del tejido previamente congelado ${ }^{1,6,30}$.

Mediante transductores transrectales ultrasónicos es posible, en tiempo real, dirigir la correcta implantación de las crioagujas y contro- 
lar la evolución del proceso de congelación ${ }^{5,6,15}$. El hielo posee una elevada impedancia acústica, capaz de reflejar hasta el 99\% del haz ultrasónico y originar una superficie claramente visible como un anillo hiperecogénico con una sombra anecoica detrás que corresponde al área de tejido congelado.

Con transductores ultrasónicos curvilíneos, la sombra acústica dificulta la visualización del límite anterior del tejido congelado y en consecuencia existe mayor riesgo de lesionar estructuras adyacentes (especialmente recto). La utilización de transductores ultrasónicos biplanares (que nos proporcionan imagen transversal y longitudinal) permite una adecuada visualización de los límites de la esfera de hielo y por tanto disminuye la probabilidad de lesiones vecinas. El empleo simultáneo de Doppler color ${ }^{6}$, puede orientar la localización del límite de la pared rectal (mayor vascularización de la mucosa) y con ello prevenir su posible lesión. La inyección ecodirigida de suero salino entre las laminas de la fascia de Denonvilliers para aumentar la separación entre próstata y recto, es otro método propuesto para disminuir el riesgo de lesiones rectales.

Con el fin de soslayar las limitaciones de los dispositivos ultrasonográficos actuales, se ha ensayado el empleo de transductores ultrasónicos tridimensionales, aunque son instrumentos con cierta complejidad para su manipulación ${ }^{35}$. En el mismo sentido, ha sido estudiada la posibilidad de controlar el proceso de congelación mediante tomografía computerizada (TC) y resonancia nuclear magnética (RNM), pues ambas proporcionan una imagen exacta de la estructura y los límites del tejido congelado. Además, la RNM tiene la ventaja de aportar información sobre las temperaturas que se alcanzan en las distintas zonas del área de tratamiento ${ }^{15,36-38}$. No obstante, toda esta tecnología tendrá utilidad en un futuro, pues actualmente presenta algunas limitaciones y no existe experiencia en su aplicación a la criocirugía prostática, además de ser costosa econonómicamente y extraordinariamente laboriosa en su práctica.

Un tercer aspecto clave de la técnica de criocirugía prostática es la protección de la mucosa uretral y el esfinter estriado mientras se realiza la ablación prostática, con la finalidad de reducir la incidencia de esfacelamiento de mucosa, estenosis uretral o incontinencia urinaria. Para ello se utiliza un calentador uretral ${ }^{39,40}$, consistente en una sonda de de doble luz con extremo ciego, por la que se hace circular constantemente suero fisiólogo a una temperatura de $38-40^{\circ} \mathrm{C}$.

Finalmente, otro detalle técnico relevante tanto para conseguir un mejor resultado terapéutico, como para prevenir las complicaciones, es la necesidad de monitorizar estrictamente la temperatura alcanzada en el área de congelación y los tejidos circundantes, para lo cual se insertan sensores térmicos tanto a través de las criosondas como en otras localizaciones ${ }^{1,30,31,40,41}$. La colocación de los mismos en zonas críticas (fascia de Denonviliers, haces neurovasculares, ápex prostático, esfínter externo), permiten disminuir notablemente la incidencia de lesiones en vecindad, especialmente las fístulas rectouretrales. En un reciente estudio experimental ${ }^{42}$, se ha utilizado un calentador eléctrico (denominado "cryoheater") asociado a las criosondas, que mediante un procedimiento de planificación computerizada permite un mejor control del daño inducido por la congelación.

\section{INDICACIONES ACTUALES}

Las indicaciones actualmente propuestas para la criocirugía en cáncer de próstata son ${ }^{1,7,43-47}$ :

1. Tratamiento primario del CaP localizado.

2. Tratamiento del fracaso bioquímico postprostatectomía o postradioterapia (externa o braquiterapia).

3. Control de complicaciones locales (hematuria, obstrucción, etc.) en pacientes con enfermedad diseminada.

La criocirugía como tratamiento electivo del carcinoma prostático localizado es propuesta para pacientes que por edad o patología concomitante (cardiopatía severa, pacientes anticoagulados, radioterapia previa por neo de recto-sigma) no son candidatos adecuados a una prostatectomía radical; o bien, pacientes que rechazan otra modalidad de tratamiento. Según se refleja en algunas series, los resultados de la criocirugía prostática en cuanto a control oncológico (supervivencia libre de enfermedad) son equiparables a los conseguidos con otras modalidades de trata- 
miento radical no cruento. Una ventaja de la crioterapia sobre otros tratamientos mínimamente invasivos es la posibilidad de repetir el tratamiento si se considera necesario ${ }^{1,7,27,34,40,48}$.

No obstante, como veremos más adelante, el análisis de los resultados de la criocirugía prostática es difícil y susceptible de critica por la heterogeneidad en los métodos de evaluación de los mismos. Además, la información sobre resultados a largo plazo es escasa, y por tanto es preciso realizar estudios prospectivos para establecer su verdadera eficacia.

Como cabría esperar, los resultados terapéuticos están claramente condicionados por los factores pronósticos tradicionales del cáncer de próstata: estadio tumoral, grado de Gleason, valor del PSA pretratamiento y volumen tumoral. Los pacientes con estadio $\leq$ T2a, Gleason $\leq 6 \mathrm{y}$ $\mathrm{PSA} \leq 10 \mathrm{ng} / \mathrm{ml}$, son los candidatos idóneos para conseguir los mejores resultados con el procedimiento. Incluso algunos investigadores proponen la práctica de una crioablación prostática selectiva unilobular ("criocirugía con conservación de haz neurovascular")cuando se trata de pacientes con pequeños tumores limitados a un único lóbulo, constituyendo la principal crítica a esta técnica la frecuencia con la que el cáncer de próstata es multifocal ${ }^{41,43,49-51}$.

Algunos consideran que en los pacientes con enfermedad clínica localizada, pero con un elevado riesgo de afectación extraprostática (estadio clínico T2b/T2c, Gleason mayor de 7, o PSA > 10 $\mathrm{ng} / \mathrm{ml}$ ), se obtiene un mejor control oncológico local con criocirugía que con radioterapia o prostatectomía radical, pues se puede ampliar el limite de la criolesión más allá de los límites prostáticos con menor riesgo de secuelas $1,24,48,52,53$. Proponen la crioterapia, también, como primera opción de tratamiento en pacientes con enfermedad localmente avanzada. En ambos casos consideran necesario el tratamiento hormonal neoadyuvante para reducir el estadio tumoral local y conseguir una crioablación más eficaz.

Un factor que condiciona las posibilidades de practicar criocirugía en el cáncer de próstata es el volumen de la glándula. En las próstatas de más de $40 \mathrm{ml}$. el proceso de congelación es más lento, se precisa una mayor cantidad de gas y aumenta el riesgo de lesión del cuello vesical y del esfinter externo. En estos casos, también, algunos aconsejan la administración previa de agonistas LH$\mathrm{RH}$ durante tres meses, ya que puede reducir el tamaño un 50\% o más, permitiendo realizar la crioablación en condiciones óptimas ${ }^{43,45-47,51}$.

Otro amplio grupo subsidiario de tratamiento con criocirugía lo constituyen los pacientes que precisan una terapia de rescate para la recurrencia local por fracaso del tratamiento primario realizado con prostatectomía radical, radioterapia (externa o intersticial) o incluso la misma criocirugía. En esta situación el riesgo de complicaciones es mucho más elevado, y por tanto es precisa una estricta selección de aquellos pacientes que puedan obtener un claro beneficio con la aplicación de este tratamiento ${ }^{43,44,47,54}$. Los criterios que deben reunir los posibles candidatos serían: confirmación de la recurrencia local mediante biopsia y técnicas de diagnóstico por imagen (TC, RNM, tomografia de emisión de positrones), descartar la presencia de enfermedad diseminada (PSA $<20 \mathrm{ng} / \mathrm{ml}$, Gleason $<8$, elevación lenta del PSA después del tratamiento primario, gammagrafía ósea negativa) y expectativa de vida mínima de 10 años. Algunos proponen la realización de una linfadenectomía laparoscópica ileo-obturatriz para descartar la existencia de adenopatias ${ }^{45}$.

Por último, la criocirugía también se ha utilizado como tratamiento paliativo de complicaciones locales en pacientes con enfermedad diseminada, tales como obstrucción infravesical o hematuria severa ${ }^{24,43,47}$.

Son contraindicaciones relativas para la práctica de la criocirugia: resección transuretral de próstata previa, estenosis de canal anal, enfermedad inflamatoria de recto y, amputación abdominoperineal ${ }^{43}$.

\section{RESULTADOS}

Es evidente la capacidad de la crioterapia para producir la erradicación de células neoplásicas, pero todavía no es posible afirmar que la próstata sea el órgano ideal para su aplicación ${ }^{55}$. Antes de considerar la criocirugía como otra opción válida para el tratamiento del cáncer de próstata es necesario aclarar algunas cuestiones relativas a la homogeneización de la técnica, criterios de selección de pacientes o tasas reales de control local y de morbilidad. 
Resulta complicado evaluar correctamente los resultados de la criocirugía prostática descritos en la literatura. Los datos recogidos son bastante heterogéneos debido a varios factores. En primer lugar hay que tener presente que la técnica de la crioablación no ha estado estandarizada hasta años muy recientes (finales de la década de los 90), por lo que en las series anteriores la metodología en cuanto a la aplicación de la técnica, selección de pacientes y protocolos de seguimiento es muy variable. A esto debemos añadir la ausencia de estudios prospectivos, con largos periodos de seguimiento que nos permitan comparar los resultados de la criocirugía con los obtenidos mediante otras terapias ya establecidas en el cáncer de próstata. La mayoría de estudios son de carácter retrospectivo y referidos a experiencias individuales. La existencia de importantes discrepancias en cuanto a los criterios para definir la eficacia del tratamiento a nivel local (sesgos en la biopsia postcriocirugía), y el fracaso bioquímico (diferentes niveles de PSA), también son criticables.

Por todo ello, a la hora de evaluar la eficacia de la CRA prostática como tratamiento electivo del cáncer, conviene analizar los resultados de forma independiente en lo referente a control local de la enfermedad y al control bioquímico (Tabla 4). Posteriormente se analizaran los resultados de la criocirugía como tratamiento de rescate.

Tabla 4

Resultados de la criocirugía prostática electiva. Control local y control bioquímico

\begin{tabular}{|c|c|c|c|c|}
\hline & No Pac & $\begin{array}{c}\text { \% Biopsia positiva } \\
\text { (tasa global) }\end{array}$ & $\begin{array}{l}\text { \% Libre recaida } \\
\text { bioquímica (mes) }\end{array}$ & $\begin{array}{c}\text { PSA nadir } \\
\mathrm{ng} / \mathrm{ml}\end{array}$ \\
\hline Bahn et al. ${ }^{1}$ & 590 & $13 \%$ & $\begin{array}{l}62(84) \\
76(84)\end{array}$ & $\begin{array}{l}<0.5 \\
<1\end{array}$ \\
\hline Han et al. ${ }^{34}$ & 122 & ND & $75(12)$ & $<0.4$ \\
\hline Paprelica et al. ${ }^{52}$ & 75 & ND & $83(35)$ & ASTRO \\
\hline Koppie et al. ${ }^{53}$ & 176 & $38 \%$ & $\begin{array}{l}62(12) \\
46(36)\end{array}$ & $\begin{array}{l}<0.5 \\
<0.5\end{array}$ \\
\hline Long et al. ${ }^{56}$ & 975 & $18 \%$ & $\begin{array}{l}* 36-60(60) \\
* 45-76(60)\end{array}$ & $\begin{array}{c}<0.5 \\
<1\end{array}$ \\
\hline Aus et al. ${ }^{58}$ & 54 & $28 \%$ & $39(60)$ & $<1$ \\
\hline Cohen et al. ${ }^{65}$ & 239 & $25 \%$ & $\begin{array}{l}57(21) \\
75(21)\end{array}$ & $\begin{array}{c}<0.4 \\
<1\end{array}$ \\
\hline
\end{tabular}

*En función de los grupos de riesgo.

\section{Evaluación de la eficacia local}

Existen discrepancias en la metodología para evaluar la eficacia en cuanto al control local de la enfermedad. La práctica de biopsia prostática postcriocirugia no ha sido generalizada; y además debemos considerar, por una parte la posibilidad de sesgos en su interpretación derivados de la utilización por algunos de tratamiento hormonal neoadyuvante, y por otra la frecuencia de resultados falsos negativos. Todo ello puede ocasionar unas tasas ficticias de pacientes libres de enfermedad.

Actualmente se tiende a la realización de la primera biopsia de control al sexto mes del procedimiento y la siguiente seis meses más tarde, espaciando las siguientes biopsias a intervalos anuales y bianuales o cuando lo indican las cifras de PSA ${ }^{1,24,56,57}$; si bien hay quien propugna realizar la primera biopsia postcriocirugia entre el tercer y sexto mes ${ }^{53,58-61}$, o quien la realiza a los 12 meses $^{7}$; y por último, quien no la realiza de forma rutinaria sino en función de la evolución del PSA ${ }^{34,46}$.

En estudios donde la primera biopsia se realiza a los 3-6 meses del tratamiento, la tasa de biopsias positivas (indicativa de carcinoma residual) oscila entre el 3.3-35\%48,56,58,59,61. Llaman la atención algunos resultados, como los reflejados en una de las primeras series de tratamiento con criocirugía, publicada en la pasada década ${ }^{61}$, que recoge la tasa de biopsias positivas a los 3,6 y 12 meses después del tratamiento, donde los resultados son $7,7,3,3$ y $2,3 \%$ respectivamente; si bien, tan sólo un $40 \%$ de los pacientes habían sido biopsiados.

$\mathrm{Si}$ analizamos las series con gran número de pacientes, generalmente sólo reflejan la tasa global de biopsias positivas, también con resultados dispares, y así encontramos que en la serie de Bahn et al. ${ }^{1}$, sobre 590 pacientes con una mediana de seguimiento de 5.7 años, la tasa global de biopsias positivas después del tratamiento es del $13 \%$, 
mientras que, en el estudio multicéntrico sobre 975 pacientes de Long et al. ${ }^{56}$ con una mediana de seguimiento de 24 meses la tasa es del 18\%; sin embargo, en la serie de Koppie et al. ${ }^{53}$, sobre 176 pacientes con un seguimiento medio de 30.8 meses esta tasa alcanza el 38\%. En un interesante estudio sobre 296 pacientes tratados en la Universidad de California-San Diego ${ }^{46}$, a los que sólo se les practica biopsia en función de la evolución del PSA o los hallazgos del tacto rectal (137 pacientes), la tasa global de resultados positivos es del 20\%; encontrando que la incidencia de cáncer residual es del $25 \%$ en los que se biopsian el primer año (63 pacientes), pero desciende al $19 \%$ para los pacientes que se biopsian después del segundo y tercer años de seguimiento (74 pacientes).

La presencia de cáncer residual puede estar influenciada por factores tales como el estadio tumoral, grado de Gleason, PSA pretratamiento o la localización ${ }^{27,43,56,59,61,62}$. La probabilidad de biopsias positivas aumenta desde el 0-9\% para estadios localizados (T1-T2) al $21-57 \%$ en estadios localmente avanzados (T3-T4). Del mismo modo, la presencia de tumor residual o la recurrencia tumoral son más frecuentes en las zonas anatómicas comprometidas como ápex (hasta un $64,2 \%)$, base prostática $(28,5 \%)$ y vesículas seminales (alrededor de un $44 \%)^{61,62}$.

De acuerdo con los estudios de Leibovich et al. ${ }^{63}$ la probabilidad de recurrencia tumoral, en los pacientes tratados con criocirugía, es mayor si el tumor es de localización periuretral ya que el calentamiento uretral inherente al proceso de crioablación dificulta conseguir las adecuadas temperaturas de congelación en las zonas próximas a la uretra. Estos autores, al analizar la pieza quirúrgica de 350 pacientes sometidos a prostatectomía radical encuentran una incidencia de cáncer de localización periuretral del $17 \%$ y que la distancia media entre la pared uretral y el foco tumoral es de $3 \pm 3 \mathrm{~mm}(0-18 \mathrm{~mm})$. Además observan que dicha distancia esta en relación directa con: el PSA pretratamiento, el grado de Gleason y el porcentaje de Gleason 4 ó 5 presentes en la biopsia. Todos estos aspectos son importantes a la hora de decidir el tratamiento con criocirugía.

La tasa de biopsias positivas varía en función de los grupos de riesgo. Así encontramos, en el estudio de Long et al. ${ }^{56}$ una tasa del $12 \%$ para el grupo de pacientes de bajo riesgo (estadio $<\mathrm{T} 2 \mathrm{a}$, $\mathrm{PSA}<10 \mathrm{ng} / \mathrm{ml}$ y Gleason $<7$ ) que se duplica en los pacientes del alto riesgo (24\%). Algo similar se observa en la serie de Bahn et al. ${ }^{1}$ con una tasa de biopsias positivas del 10-15\% para los pacientes de riesgo bajo e intermedio, que llega al $26 \%$ en el grupo de pacientes de alto riesgo. No obstante, otros autores no encuentran diferencias significativas a este respecto ${ }^{40,52}$.

Comentábamos, al hablar de los fundamentos biológicos de la criocirugía, que el número de ciclos de congelación-descongelación es un hecho fundamental para conseguir la adecuada ablación del tejido neoplásico. La experiencia clínica confirma este aspecto, y así vemos como la tasa de biopsias positivas desciende desde un 64-75\% en los pacientes tratados con un solo ciclo al 11$17 \%$ en los sometidos a dos ciclos de congelacióndescongelación ${ }^{24,62}$. En este mismo sentido, en diferentes estudios se recurre a la repetición del procedimiento dos o más veces para tratar el cáncer residual: en la serie de Wong et al. ${ }^{40}$ con un segundo procedimiento de crioablación se reduce la incidencia de cáncer residual del $21 \%$ al $6 \%$; de igual modo, Saliken et al. ${ }^{64}$ consiguen reducir la tasa de biopsias positivas desde un $14 \%$ en los primeros 6 meses postratamiento al 1\%, mediante un segundo, e incluso un tercer procedimiento de criocirugía. En una serie española publicada recientemente ${ }^{57}$, sobre 20 pacientes tratados, la tasa de resultados positivos en 19 pacientes biopsiados a los 6 meses es del 11\% (2/19), mientras que a los 12 meses (con dos pacientes sometidos a un segundo procedimiento de criocirugía) sólo un paciente presentaba cáncer; y en 18 pacientes biopsiados a los 24 meses, ninguno presenta cáncer en la muestras obtenidas.

Otro factor que influye en la presencia de carcinoma residual en las biopsias postablación es el empleo de terapia hormonal neoadyuvante. En el estudio de Cohen et al. ${ }^{65}$ sobre 114 pacientes que fueron biopsiados a lo largo de un periodo de seguimiento de 21 meses o superior, observan que en el grupo de pacientes sin tratamiento neoadyuvante (83/114) el $21 \%$ presentó biopsias positivas, mientras que en el grupo que recibió hormonoterapia (31/114) sólo en el 13\% de los pacientes aparecía tumor residual. Igualmente, el 
estudio de la Universidad de San Francisco ${ }^{62}$, muestra que en pacientes tratados con bloqueo hormonal (65 pacientes) la incidencia de cáncer residual es del $22 \%$, en comparación con el $33 \%$ de los pacientes que no habían recibido dicho tratamiento (45 pacientes).

Estos resultados también se ven influenciados por la técnica empleada y las características de los aparatos de crioterapia. Por ejemplo, en el estudio de la Universidad de Columbia ${ }^{40}$, llama la atención una tasa de biopsias positivas extraordinariamente alta $(83 \%)$ en el primer grupo de pacientes tratados, en el que no se disponía de sensores térmicos para control de temperatura; mientras que en el grupo de pacientes en que se utilizaron sensores térmicos la cifra desciende al $9 \%$. Igualmente, se observa como la tasa de biopsias positivas disminuye con la introducción de los equipos de criocirugía de última generación, bajando del 35 al 15\%48.

Un acontecimiento paradójico y no infrecuente es la presencia de focos de tejido epitelial benigno viable en las biopsias postcriocirugia, que puede ser encontrado en un $71 \%$ de los pacientes $(60 \%$ si sólo se consideran pacientes tratados con doble ciclo de congelación-descongelación) ${ }^{24}$, y cuyo verdadero significado es incierto: ¿se trata de zonas de no congelación por no alcanzar la temperatura adecuada, o bien son focos de reepitelización a partir de zonas no congeladas (como el epitelio uretral)?

$\mathrm{Si}$ asumimos el primer supuesto, tendremos que concluir que por el mismo motivo podrian quedar zonas de tejido neoplásico viables, como demuestra un estudio de Pisters et al. ${ }^{29}$ en el que realizan prostatectomía radical con criocirugía neoadyuvante a pacientes con cáncer de próstata localmente avanzado. Al analizar las piezas de prostatectomía encuentran que todos los pacientes presentan zonas de tejido epitelial viable $\mathrm{y}$, que en el $66 \%$ de las piezas que presentan tumor residual este se localiza en la zona periuretral (que alcanza menores temperaturas de congelación por el uso de calentadores uretrales).

Dada la tendencia a la multifocalidad del cáncer de próstata, la probabilidad de encontrar cáncer residual aumentara en los casos en los que la biopsia presenta tejido glandular viable (como expresión de una deficiente congelación), y algu- nos encuentran que la presencia de cáncer residual se correlación directamente con el porcentaje de tejido glandular viable existente en la biopsia postcriocirugía ${ }^{48,66}$.

Además, en el estudio de Shuman et al. ${ }^{66}$ se observa que la probabilidad de encontrar elementos glandulares en la biopsia aumenta conforme aumenta el periodo de tiempo transcurrido desde el momento de la criocirugía. La insuficiente congelación del tejido favorece el crecimiento de los focos de tejido glandular viable con el paso del tiempo, lo cual se manifestará a nivel clínico con una elevación el las cifras del PSA, hecho que acontece en un 50\% de los pacientes estudiados por estos autores.

En un estudio realizado sobre piezas de prostatectomía de rescate postcriocirugía ${ }^{67}$ se observa que en todos los casos analizados coexisten, junto con el tejido neoplásico, áreas de tejido con los cambios propios de la crioablación (necrosis, hialinización, metaplasia de epitelio transicional, edema e infiltrado celular inflamatorio) y tejido prostático benigno completamente normal, indicativo de la presencia de zonas de congelación insuficiente, a pesar de haber realizado un adecuado control ecográfico (inclusión completa de la próstata en la "bola de hielo") durante el procedimiento de la criocirugía.

En este mismo sentido, en el estudio español realizado por Escudero et al. ${ }^{68}$ al analizar las biopsias postcriocirugía, se encuentran diferencias en cuanto al volumen de tejido afectado por la congelación entre los pacientes en los que se detecta cáncer residual (menos del 60\% del tejido presentaba signos de congelación) y los que presentaban biopsias libres de tumor (más del 70\% de tejido congelado).

La hipótesis que considera el origen del tejido epitelial glandular viable como un fenómeno de reepitelización que surge a partir de focos de epitelio transicional de la pared uretral conservada, ha sido sustentada a partir de modelos de experimentación animal ${ }^{69}$.

\section{Evaluación del fracaso bioquímico}

A la hora de evaluar la recaída bioquímica del paciente tratado mediante criocirugía prostática es importante tener presente algunos aspectos. En primer lugar, hay que decir, que todavía no 
esta establecido que cifra de PSA postratamiento debe considerarse como indicativa del éxito terapéutico. Al igual que acontece en los pacientes tratados con radioterapia externa o braquiterapia, en los tratados con criocirugía el descenso del valor de PSA es paulatino y suele tardar algunos meses en alcanzar la cifra nadir. Además, es frecuente observar un incremento del nivel de PSA inmediatamente después de la crioablación (consecuencia de la liberación masiva del antígeno debida a la necrosis celular) y un descenso posterior más lento de lo cabria esperar de acuerdo a la vida media del PSA ${ }^{59,70}$.

Como la criocirugía no elimina completamente el tejido prostático (como hemos comentado anteriormente), los niveles detectables de PSA pueden ser consecuencia tanto de la presencia de tejido glandular benigno como de la de tejido neoplásico residual no erradicados por la congelación. Por tanto, al igual que ocurre con la radioterapia, la presencia de unas cifras bajas pero estables de PSA no es sinónimo de progresión de la enfermedad, pudiendo establecer una cierta correlación entre la obtención de un nivel de PSA nadir y la recurrencia o progresión del tumor ${ }^{43,62,71}$. En el trabajo de Shuman et al. ${ }^{66}$ se observa que una elevación de PSA lenta (más de 6 meses) esta en relación con un incremento, en la biopsia prostática, de la cantidad de epitelio glandular normal sensible a la acción de la testosterona; por el contrario, un aumento rápido de la cifra de PSA (en los primeros meses postratamiento) suele estar en relación con la existencia de cáncer residual en la biopsia. En este mismo sentido, en el estudio de la Universidad de San Francisco ${ }^{62}$, se aprecian hallazgos similares: los pacientes que alcanzan un PSA nadir $<0,1 \mathrm{ng} / \mathrm{ml}$ presentan una tasa de biopsias con cáncer residual del 1,5\%, mientras aquellos en los que el PSA nadir no desciende por debajo de $0,5 \mathrm{ng} / \mathrm{ml}$ tiene una tasa de de biopsias positivas del $55 \%$. Otros autores, observan este mismo hecho ${ }^{61,65}$.

No existe todavía un consenso para definir la recidiva bioquímica de la enfermedad en los pacientes tratados con criocirugía. Podemos encontrar innumerables trabajos con diferentes criterios a la hora de establecer qué valores nadir de PSA definen la enfermedad libre de progresión bioquímica: hasta 0,2 ó $0,3 \mathrm{ng} / \mathrm{ml}$ para unos, hasta $0,4 \mathrm{ng} / \mathrm{ml}$ o $0,5 \mathrm{ng} / \mathrm{ml}$ para otros, e incluso para algunos cifras de hasta $1 \mathrm{ng} / \mathrm{ml}$ son aceptadas como indicativas de curación ${ }^{1,34,56,58,62}$, y hasta $2 \mathrm{ng} / \mathrm{ml}$ en tratamientos de rescate postradioterapia ${ }^{54}$.

Por la similitud con la radioterapia, algunos proponen seguir los criterios de la ASTRO (American Society for Therapeutic Radiology Oncology), considerando tres elevaciones sucesivas de la cifra de PSA como recaída bioquímica. Lógicamente es difícil establecer comparaciones entre la criocirugía y la radioterapia en base a estudios retrospectivos, entre otros motivos porque en la mayoría de series de pacientes tratados con crioterapia no se alcanzan los largos seguimientos reflejados en las series de radioterapia (en la mayoría superiores a 10 años)

Además, la utilización de tratamiento hormonal neoadyuvante en muchos pacientes, constituye otro factor distorsionante que hace aún más dificil saber que pacientes son realmente curados por la criocirugía. Como se demuestra en un estudio, el bloqueo androgénico previo a la criocirugia influye positivamente en la probabilidad de recidiva bioquímica: $11 \%$ en pacientes con cáncer estadio T1-T2 tratados con neoadyuvancia frente al $55 \%$ en los no tratados ${ }^{62}$; si bien, también hay que observar que la neoadyuvancia se asocia a mayor tasa de fracaso bioquímico ${ }^{56}$ (aunque hay que considerar el sesgo que supone que la mayoría de los pacientes con neoadyuvancia eran de mal pronóstico).

Todos estos aspectos hacen difícil evaluar de un modo objetivo y con criterios homogéneos los verdaderos resultados de la criocirugía sobre el control bioquímico de la enfermedad. Si se estableciera el nadir de $0,4 \mathrm{ng} / \mathrm{ml}$ para definir la supervivencia libre le enfermedad, los resultados obtenidos con crioterapia (de segunda y tercera generación) no superarían los reflejados en las principales series de cirugía radical o braquiterapia $^{55}$. No obstante, cuando analizamos las series con mayor número de pacientes y mayor seguimiento nos encontramos con resultados muy heterogéneos.

En el estudio multicéntrico con 975 pacientes de Long et al. ${ }^{56}$ se clasifica a los pacientes en grupos de riesgo y la supervivencia libre de progresión bioquímica encontrada a los 5 años oscila, 
en los pacientes de bajo riesgo, entre el $60-76 \%$ dependiendo del nadir de PSA $(<0,5 \mathrm{ng} / \mathrm{ml}$ o $<1$ $\mathrm{ng} / \mathrm{ml}$ respectivamente); mientras que en los pacientes de alto riesgo se sitúa entre el 36-45\% dependiendo del nadir considerado. El 33\% de los pacientes habian recibido tratamiento neoadyuvante con bloqueo androgénico completo durante 3-8 meses, especialmente los que presentaban características de peor pronóstico.

En la serie de Bahn et al. ${ }^{1}$ constituida por 590 pacientes con un seguimiento medio superior a 5 años, se clasifica a los pacientes en grupos de riesgo y se consideran diferentes umbrales de PSA para definir el fracaso bioquímico. Presentan una supervivencia actuarial a 7 años libre de progresión considerando tres valores diferentes de nadir de PSA: cuando es $<0,5 \mathrm{ng} / \mathrm{ml}$, la supervivencia es del $61 \%$, 68\% y $61 \%$ para pacientes de bajo, medio y alto riesgo respectivamente; si se considera el nadir de PSA $<1 \mathrm{ng} / \mathrm{ml}$, con un $87 \%$, $79 \%$ y $71 \%$ respectivamente; y al utilizar los criterios de fracaso bioquímico de la ASTRO es de un $92 \%, 89 \%$ y $89 \%$. La supervivencia global libre de recaída bioquímica, según el umbral de PSA considerado, es de $62 \%, 76 \%$ y $89.5 \%$ respectivamente. Más del 90\% de los pacientes habían recibido bloqueo androgénico completo durante 3-12 meses previos a la criocirugía.

La serie de 176 pacientes tratados en la Universidad de San Francisco ${ }^{53}$, incluye pacientes con cáncer en estadios T1-T4 que recibieron 207 tratamientos de criocirugía. El 57\% de los pacientes recibieron tratamiento hormonal neoadyuvante, y en 35 pacientes la crioterapia constituía un tratamiento de rescate (postcirugía o postradioterapia). El fracaso bioquímico se establece cuando el PSA nadir es $>0,5 \mathrm{ng} / \mathrm{ml}$ o se produce un incremento $>0,2 \mathrm{ng} / \mathrm{ml}$ en dos determinaciones consecutivas. Los pacientes en los que la criocirugía es el tratamiento primario muestran una supervivencia actuarial libre de recidiva bioquímica del $62 \%$ en los primeros 12 meses, que desciende al $46 \%$ a los 36 meses; en los pacientes considerados de bajo riesgo es del $82 \%$ y $69 \%$ respectivamente, y en los de alto riesgo del $58 \%$ y $45 \%$ a los 12 y 36 meses, respectivamente.

Un hallazgo interesante, encontrado por este grupo, es que el fracaso bioquímico es mucho menos frecuente en los pacientes que alcanzan un nadir de PSA $<0,1 \mathrm{ng} / \mathrm{ml}$ (recaída en el $5 \mathrm{y}$ $23 \%$ de casos a los 12 y 36 meses, respectivamente), si los comparamos con los que no consiguieron un nadir de PSA inferior a $0,5 \mathrm{ng} / \mathrm{ml}$ (con tasas de recaída bioquímica del 92 y 100\%, respectivamente).

En un estudio prospectivo, desarrollado en Boston $^{60}$ con 145 pacientes con cáncer de próstata clínicamente localizado y con un seguimiento medio de 36 meses, se considera la supervivencia libre de recurrencia bioquímica tanto un umbral de PSA de $<0,3 \mathrm{ng} / \mathrm{ml}$, como uno de $<1$ $\mathrm{ngr} / \mathrm{ml}$ por analogía con los estimados para la prostatectomía y radioterapia, respectivamente. En un $88 \%$ de los pacientes no había existido ningún tratamiento local previo y en 45 de ellos se administro tratamiento hormonal previo a la criocirugía. La supervivencia actuarial libre de progresión bioquímica a los 42 meses es del 59\% si se considera el nivel de PSA $<0,3 \mathrm{ng} / \mathrm{ml}$ y del $66 \%$ si se considera el umbral de $<1 \mathrm{ng} / \mathrm{ml}$.

El estudio de Cohen et al. ${ }^{65} 239$ pacientes son tratados con crioterapia electiva, ninguno de los cuales recibe hormonoterapia y 163 de ellos tienen determinaciones de PSA durante un seguimiento mínimo de 21 meses. El 57\% de los pacientes presentan un PSA $<0,4 \mathrm{ng} / \mathrm{ml}$ y el $75 \%$ un PSA $<1 \mathrm{ng} / \mathrm{ml}$.

Han et al. ${ }^{34}$ empleando dispositivos de criocirugía de última generación, realizan un estudio multicéntrico con 122 pacientes con un seguimiento mínimo de 12 meses. En el 85\% el tratamiento es electivo y en un $37 \%$ de ellos se utiliza hormonoterapia neoadyuvante. Definen el fracaso bioquímico cuando el nadir de PSA es $\geq 0,4$ $\mathrm{ng} / \mathrm{ml}$. La supervivencia global libre de recurrencia bioquímica a los 12 meses es de un 75\% (78\% en pacientes de bajo riesgo y $71 \%$ en pacientes de alto riesgo).

Un grupo de la Universidad de Goteborg ${ }^{58}$, llevó a cabo un estudio prospectivo sobre 54 pacientes con cáncer de próstata estadios T1-T3 y Gleason 2-10, la mayoría sin ningún tratamiento local previo, con un seguimiento medio superior a 58 meses. Definen como progresión bioquímica un umbral de PSA $>1 \mathrm{ng} / \mathrm{ml}$. La supervivencia global actuarial a 5 años libre de recurrencia es del 39\%; y sorprendentemente, en 
el grupo de pacientes de bajo riesgo sólo alcanza el $30 \%$. El $76 \%$ de los pacientes recibió tratamiento hormonal neoadyuvante.

El grupo de la Universidad de Columbia ${ }^{52}$, realiza un estudio retrospectivo de 75 pacientes con cáncer de próstata con estadios T1-T3, que presentaban características de alto riesgo de progresión (PSA >10 ng/ml y/o Gleason >8), empleando la criocirugía como tratamiento electivo. Un $68 \%$ de los pacientes son tratados con neoadyuvancia hormonal. Definen el fracaso bioquímico de acuerdo a los criterios de la ASTRO. Con un seguimiento de 35 meses, la supervivencia libre de recaída bioquímica es del $83,3 \%$. También observan que un $80 \%$ de los pacientes presentan un nadir de PSA $<1 \mathrm{ng} / \mathrm{ml}$ a los 24 meses del procedimiento.

En el estudio prospectivo de Donnelly et $\mathrm{al}^{72}$, sobre un grupo de 76 pacientes sin ningún tratamiento local previo y excluyendo pacientes de alto riesgo, la supervivencia libre de progresión bioquímica a los 5 años es del 59\% o del 79\% según se considere el umbral de PSA de 0,3 $\mathrm{ng} / \mathrm{ml}$ o de $1 \mathrm{ng} / \mathrm{ml}$, respectivamente.

En la serie de 20 pacientes del grupo español ${ }^{57}$, con un seguimiento que varia entre 30 y 36 meses y sin empleo de hormonoterapia neoadyuvante, se evalúan los resultados considerando diferentes nadires de PSA: $0,2 \mathrm{ng} / \mathrm{ml} ; 0,5 \mathrm{ng} / \mathrm{ml}$; $\leq 1,0 \mathrm{ng} / \mathrm{ml} \mathrm{y}>1,0 \mathrm{ng} / \mathrm{ml}$. A los 3 meses del tratamiento, alcanzan dichos niveles el 78,9\%; 89,4\%; 94,7\%; y 5,26\% de los pacientes, respectivamente; mientras que a los 30 meses esos mismos nadires se observan en un 27,8\%; 50\%; $66,6 \%$ y $33,3 \%$ de los pacientes, respectivamente.

En un interesante estudio retrospectivo, desarrollado por Gould ${ }^{73}$, se comparan los resultados obtenidos al tratar 159 pacientes con cáncer en estadios T1c-T2b mediante prostatectomía radical perineal (83 casos), criocirugía convencional (49 casos) y criocirugía "radical", sin calentamiento uretral (27 casos). La supervivencia libre de enfermedad se establece sobre un nivel de PSA $<0,2 \mathrm{ng} / \mathrm{ml}$ a los 6 meses del tratamiento. El 73\% de los pacientes tratados con cirugía, el $49 \%$ de los tratados con criocirugía convencional y el $96 \%$ de los sometidos a criocirugía radical mantienen unos niveles de PSA $<0,2 \mathrm{ng} / \mathrm{ml}$ a $\operatorname{los} 6$ meses del tratamiento. El análisis con un seguimiento medio de 12 meses revelaba un mayor incremento de la media de PSA para el grupo de pacientes prostatectomizados (de 0,42 a 0,69), que para el de los tratados con criocirugía radical (de 0,04 a 0,48). No estante, la tasa de complicaciones fue mucho más elevada en este ultimo grupo.

\section{Resultados de la criocirugia de rescate}

La CRA es factible en el tratamiento de aquellos pacientes previamente tratados mediante distintas formas de radioterapia que presentan carcinoma prostático residual o desarrollan una recurrencia local a lo largo del seguimiento ${ }^{51,54,74-76}$. Además, los resultados de la criocirugía, como terapia de rescate, han ido mejorando paulatinamente en relación directa con el desarrollo técnico acontecido en este campo. La elevada morbilidad que presenta la prostatectomía de rescate después del fracaso de la radioterapia, convierte a la crioablación prostática en una opción terapéutica atractiva; aunque, esta tampoco está exenta de complicaciones y así, encontramos reflejada en la literatura una tasa de incontinencia urinaria que alcanza el $73 \%$, de obstrucción postoperatoria del $67 \%$ y la de disfunción eréctil que puede alcanzar el 100\%47,77.

No obstante, a la hora de evaluar los resultados conseguidos con esta modalidad de tratamiento, nos encontramos con los mismos problemas que exponíamos al hablar de de crioterapia electiva: estudios retrospectivos, la mayoría con pocos pacientes y cortos periodos de seguimiento, grupos de pacientes muy heterogéneos, uso de hormonoterapia neoadyuvante, diferentes criterios de fracaso bioquímico, etc. (Tabla 5).

Resulta obvio, al igual que en cualquier grupo de pacientes con cáncer de próstata, que una adecuada selección de los mismos es esencial para obtener los mejores resultados con la criocirugía de rescate. Los pacientes en los que la criocirugía de rescate tiene peores resultados son aquellos en los que la recurrencia postradioterapia presenta características de mal pronóstico como: PSA pretratamiento con crioablación $>10 \mathrm{ng} / \mathrm{ml}$, un Gleason $>8$, estadio clínico inicial localmente avanzado o pacientes que han precisado tratamiento con neoadyuvancia hormonal ${ }^{54,78}$. 
Tabla 5

Resultados de la criocirugía prostática de rescate. Control bioquímico

\begin{tabular}{|c|c|c|c|}
\hline & No Pac & $\begin{array}{c}\text { \% Libre recaida } \\
\text { bioquímica (mes) }\end{array}$ & $\begin{array}{c}\text { PSA nadir } \\
\mathbf{n g} / \mathbf{m l}\end{array}$ \\
\hline Izawa et al. ${ }^{78}$ & 131 & $40(60)$ & $<2$ \\
\hline Chin et al. ${ }^{79}$ & 118 & $\begin{array}{l}34(19) \\
55(19) \\
68(19)\end{array}$ & $\begin{array}{c}<0.5 \\
<2 \\
<4\end{array}$ \\
\hline Bahn et al. ${ }^{81}$ & 59 & $\begin{array}{l}59(72) \\
69(72)\end{array}$ & $\begin{array}{c}<0,5 \\
<1\end{array}$ \\
\hline Ghafar et al. ${ }^{76}$ & 38 & $\begin{array}{l}86(12) \\
74(24)\end{array}$ & $\begin{array}{l}<0,3 \\
<0,3\end{array}$ \\
\hline
\end{tabular}

La serie más numerosa descrita hasta el momento en la literatura, es la de Pisters et al. ${ }^{47}$ que reunió 150 pacientes que habían sido tratados con radioterapia (sola en 110 casos, y asociada a hormonoterapia y/o quimioterapia en 40), que tuvieron un seguimiento medio de 17,3 meses. Antes del tratamiento primario, el 60\% los pacientes habían sido diagnosticados de carcinoma prostático en estadio $\geq$ T3 y un 59\% tenían un grado de Gleason 8-10.

En dicha serie, la tasa de biopsias negativas al sexto mes del procedimiento fue del 77\% (85/110 pacientes biopsiados). De 146 pacientes que disponían de determinaciones de PSA durante el seguimiento, un 58\% (85/146) sufrió recurrencia bioquímica (definida como una elevación $\geq 0,2 \mathrm{ng} / \mathrm{ml}$ sobre el PSA nadir), un 31\% (45/146) presentaba un PSA "indetectable" (definido como PSA $<0,1$ $\mathrm{ng} / \mathrm{ml})$ y el $11 \%$ restante $(16 / 146)$ tenia un PSA "detectable pero estable" ((no superaba 0,2 ng/ml o el PSA nadir). La tasa de recurrencia bioquímica fue menor en el grupo de pacientes que había recibido exclusivamente radioterapia como tratamiento primario en comparación con el grupo tratado con combinación de radioterapia y hormono/quimioterapia (54\% vs 71\%), y los mismo ocurrió con la tasa de biopsias positivas postcriocirugía (18\% vs $36 \%$ ).

En una revisión posterior, estos autores estudian la supervivencia actuarial libre de enfermedad bioquímica a los 5 años de los 131 pacientes que alcanzaron un mayor seguimiento (mediana de 4,8 años). Considerando como fracaso bioquímico un PSA $>2 \mathrm{ng} / \mathrm{ml}$ por encima del valor nadir, la supervivencia libre de enfermedad llega- ba al 40\%. Al clasificar a los pacientes en función de los factores de riesgo, encuentran que la supervivencia es significativamente mayor en los tratados exclusivamente con radioterapia (48\% vs $22 \%$ ), en los que tienen un PSA precriocirugía $\leq 10 \mathrm{ng} / \mathrm{ml}$ (57\% vs 23\%) o un Gleason $\leq 8$ (46\% vs $31 \%$ ) y en los que el estadio clínico preradioterapia es menor de T3 $(90 \% \text { vs } 69 \%)^{78}$.

La serie de Chin et al. ${ }^{79}$ consta de 118 pacientes con un seguimiento medio de 18,6 meses, un $60 \%$ de los cuales recibió hormonoterapia neoadyuvante. Estos autores encuentran una supervivencia libre de recurrencia bioquímica del 68\%, $55 \%$ y $34 \%$ según se considere la definición de fracaso bioquímico como $\mathrm{PSA} \geq 4, \geq 2$ o $\geq 0,5$ $\mathrm{ng} / \mathrm{ml}$, respectivamente. Este mismo grupo, en una revisión más tardía, encuentra una tasa de un $14,2 \%$ de biopsias con tejido neoplásico postcricirugía en los 103 pacientes que habían alcanzado un mayor seguimiento; además, un 42,4\% presentan tejido glandular viable en la biopsia ${ }^{80}$. También observan, que un PSA preocriocirugía > $10 \mathrm{ng} / \mathrm{ml}$, un Gleason de 8-10 y/o un estadio> T3-4 son factores que elevan notablemente las probabilidades de recaída bioquímica.

En un grupo de 59 pacientes con tumores estadios T1-3, tratados con criocirugía de rescate y hormonoterapia neoadyuvante, y seguidos durante un periodo de 7 años, la supervivencia libre de enfermedad bioquímica es del 59\% y 69\% según se defina el nivel de PSA $<0,5$ o $<1 \mathrm{ng} / \mathrm{ml}$, respectivamente. No hubo pacientes con biopsia positiva después de la criocirugía ${ }^{81}$.

Por último, el grupo de la Universidad de Columbia ${ }^{76}$, trata 38 pacientes mediante criocirugía de rescate y terapia hormonal neoadyuvante. El seguimiento medio es de 20,7 meses. La supervivencia libre de recaída bioquímica (definida por un incremento $>0,3 \mathrm{ng} / \mathrm{ml}$ sobre el PSA nadir) es del $86 \%$ a los 12 meses y del $74 \%$ a los 24 meses.

\section{Criocirugía con conservación de parénquima}

Actualmente, sobre la base de recientes estudios (tanto experimentales como de ámbito clinico), se comienza a plantear la posibilidad de criocirugía selectiva con conservación glandular y de haces neurovaculares ${ }^{43,49,50,82,83}$, con la finalidad de disminuir la incidencia de efectos secundarios (especialmente impotencia e incontinencia). 
En un estudio de Rukstalis et al. ${ }^{82}$ que analiza las características histopatológicas de 112 piezas de prostatectomía radical, encuentran unos interesantes hallazgos: prácticamente el $80 \%$ de los casos presentan cáncer multicéntrico, más del 70\% de los pacientes presentan menos de tres focos tumorales, la mediana del volumen del tumor principal es 1,6 cc y la mediana del volumen de los focos tumorales secundarios es 0,3 cc, un $66 \%$ de los pacientes presentan tumor en un área de $5 \mathrm{~mm}$ próxima a la uretra y un $45 \%$ tienen tumor en un radio de $1 \mathrm{~mm}$ alrededor de la uretra; además observan que un volumen tumoral $>2$ cc y un valor de PSA > de $10 \mathrm{ng} / \mathrm{ml}$ se asocian de forma significativa con la presencia de cáncer periuretral. Sobre estos datos calculan las posibilidades de cáncer residual si se realizara un crioablación selectiva del foco tumoral principal y un adecuado margen del tejido circundante ipsilateral, y encuentran que el $21 \%$ de los pacientes tendrían riesgo de presentar un cáncer residual de un volumen significativo ( $>$ $0,5 \mathrm{cc}$ ); siendo el área periuretral, la zona donde más probablemente persista tejido canceroso, debido a una congelación insuficiente por la necesidad de calentamiento uretral.

Estos mismos investigadores, también concluyen que en los tumores localizados en la región basal o medial de la zona periférica se pueden utilizar temperaturas máximas de calentamiento uretral para minimizar el riesgo de lesión uretral, pues la probabilidad de cáncer residual periuretral es menor. Mientras que tumores voluminosos, o con PSA > $10 \mathrm{ng} / \mathrm{ml}$ o de localización apical deben someterse a la temperatura más baja posible por el mayor riesgo de persistencia de células neoplásicas, asumiendo la mayor probabilidad de daño uretral.

Otro estudio experimental ${ }^{83}$, realizado en animales, estudia la probabilidad de tejido viable residual en la zona periférica adyacente a los haces neurovasculares cuando se realiza crioablación prostática con calentamiento activo de los haces. Se obtienen dos interesantes conclusiones con repercusión en la "criocirugía conservadora”: por un lado, que en todos los casos en los que se realiza calentamiento de haces, estos se preservan total o parcialmente; por otro, que en un $57 \%$ de esos casos persiste tejido prostático viable adyacente a la zona de calentamiento.
A nivel clínico, encontramos alguna experiencia sobre criocirugía con conservación neurovascular. En el estudio de Onik et al. ${ }^{49}$ en nueve pacientes con un seguimiento medio de 36 meses, en los que se practicó "crioablación conservadora"; en seis pacientes realizaron biopsias tanto de la zona congelada como de las áreas no tratadas y encontraron que en ningún caso existía tejido neoplásico en las biopsias de la zona congelada y, sólo en un paciente, se observó la presencia de neoplasia intraepitelial de bajo grado en las biopsias de la zona no tratada.

En otro estudio sobre seis pacientes, con un seguimiento de 12-88 meses, tratados de forma conservadora (con crioablación de un solo lóbulo) por el grupo de la Universidad de CaliforniaSan Francisco ${ }^{43}$, no encuentran en ningún caso tejido neoplásico ni en las biopsias del lóbulo tratado ni en las del lóbulo contralateral. Una observación importante es que este grupo no practica esta modalidad de tratamiento con intención de radicalidad oncológica, sino como un método preventivo de la progresión tumoral en un grupo de pacientes de bajo riesgo, que también podrían haber sido candidatos a un protocolo de vigilancia.

\section{COMPLICACIONES DE LA CRIOCIRUGÍA PROSTÁTICA}

Si bien la CRA prostática percutánea constituye un procedimiento mínimamente invasivo, seguro y familiar para el urólogo, es una técnica que no está exenta de morbilidad. Como vimos al principio, esta ha disminuido dramáticamente coincidiendo con la introducción de algunos adelantos tecnológicos como son la ultrasonografia transrectal, los calentadores uretrales o el empleo de criosondas de fino calibre o crioagujas. Como es obvio, además de los avances técnicos y la destreza del cirujano, la incidencia de complicaciones está notablemente condicionada por la selección de los pacientes candidatos a esta modalidad terapéutica. Específicamente, los pacientes previamente irradiados presentan una tasa de complicaciones mucho más elevada.

Las secuelas más preocupantes del tratamiento y que suelen manifestarse ya en las primeras semanas después del tratamiento, son: incontinencia urinaria, fístula rectouretral, impotencia y 
obstrucción infravesical secundaria la esfacelamiento uretral, que se presentan con una frecuencia variable. Algunas otras como dolor pélvico, perineal o escrotal, entumecimiento del pene, estenosis uretral, hematuria, infección del trato urinario, epididimitis, obstrucción uretral e hidronefrosis, obstrucción intestinal u osteítis de pubis, también han sido descritas $1,24,46,47,53,77$. Una temperatura de congelación demasiado baja o una deficiente protección de los tejidos circundantes, son los dos mecanismos normalmente implicados en la aparición de la lesiones postcriocirugia.

La frecuencia de estas complicaciones es variable según las diferentes series. Esta variabilidad se ve favorecida en algunos casos, como la incontinencia o la impotencia, por la disparidad existente en los criterios establecidos a la hora de definir estos sintomas (Tabla 6).

Por su frecuencia y trascendencia clínica, la disfunción eréctil constituye la complicación más importante. La criocirugía daña las estructuras neurovasculares responsables de la erección, por lo que la impotencia en los primeros meses después del procedimiento es generalizada, a lo cual ayuda la utilización en muchas ocasiones de hormonoterapia neoadyuvante. Pasado ese periodo, los mecanismos de regeneración neuronal permiten que algunos enfermos consigan cierto grado de erección, lo cual suele acontecer 2 o 3 años después de realzado el tratamiento. Si bien con los aparatos de crioterapia de primera y segunda generación se alcanzaba una incidencia prácticamente del $100 \%$, con la intro-

Tabla 6

Complicaciones de la criocirugía prostática electiva (\%)

\begin{tabular}{|c|c|c|c|c|c|c|}
\hline & $\mathbf{D E}$ & IU & E. Uretra & Obstrucción & Dolor & Fistula U-R \\
\hline Bahn et al. ${ }^{1}$ & 95 & 4,3 & 3,9 & 5,5 & ND & 0,1 \\
\hline Ellis $^{7}$ & 82,4 & 5,5 & 6,7 & 6,7 & ND & 0 \\
\hline Shinohara et al. ${ }^{24}$ & 84 & 4 & ND & 23 & 3 & 1 \\
\hline Han et al. ${ }^{34}$ & 87 & 3 & 5 & ND & 6 & 0 \\
\hline Long et al. ${ }^{56}$ & 93 & 7,5 & 0 & 13 & ND & 0,5 \\
\hline Aus et al. ${ }^{58}$ & 90,6 & 18,5 & 14,8 & 16,6 & ND & 0 \\
\hline Coogan et al. ${ }^{71}$ & 47 & 3 & 9 & 5 & 1 & 1 \\
\hline
\end{tabular}

$\mathrm{DE}=$ Disfunción eréctil; IU= Incontinencia; E, Uretra= Esfacelamiento; Fístula U-R= Uretro-rectal; $\mathrm{ND}=$ No especificado. ducción de aparatos de última generación ha sido posible disminuir ligeramente esa incidencia a cifras que rondan $80-95 \%$ según la mayoría de series $1,7,24,34,56,58$; aunque algunas describen tasas mucho más bajas, incluso por debajo del $50 \%{ }^{71,84,85}$.

En casos muy seleccionados, algunas series reflejan una tasa llamativamente elevada de recuperación de la función eréctil. En concreto en el estudio de Onik et al. ${ }^{49}$ en un grupo de pacientes tratados con técnica de "crioterapia conservadora" (9 pacientes con tumor unilateral y volumen tumoral bajo) refiere un conservación de potencia del $78 \%$, sin evidencia de recurrencia de la enfermedad. Este hecho contrasta con una interesante observación, reflejada en el estudio de la $\mathrm{UCSF}^{27}$ (donde la tasa de disfunción eréctil alcanza el $84 \%$ ), y es que de 11 pacientes que recuperaron la potencia, el 36\% tenía biopsia postcriocirugía positiva y el $88 \%$ un PSA detectable durante el seguimiento, lo que podría implicar una congelación insuficiente.

En un estudio sobre 75 pacientes tratados con criocirugía realizado por Robinson et al. ${ }^{84}$ se estudia la recuperación de la función eréctil, mediante la utilización de un cuestionario (38 de 49 pacientes sexualmente activos previamente contestaron). Se cifra en un 13\% (5 de 38) la tasa de pacientes que recuperan la situación basal pretratamiento después de tres años de la crioablación y, además otro $34 \%$ (13 de 38) consigue una erección satisfactoria con el empleo de algún tipo de tratamiento para la disfunción eréctil (sildenafilo, inyección intracavernosa, etc.).

Otra complicación de notable trascendencia clínica para los pacientes tratados con criocirugía es la incontinencia urinaria., cuya incidencia es variable dependiendo fundamentalmente de la definición empleada. Actualmente el criterio más utilizado para su cuantificación es el número de absorbentes utilizado. La mayoría de los pacientes presentan, en las primeras semanas después del tratamiento, una incontinencia 
leve o moderada que suele recuperase mediante ejercicios de rehabilitación del suelo pelvico en los 6 primeros meses. En pacientes tratados de forma electiva con crioablación, entre el $2-15 \%$ necesitan usar absorbentes $\mathrm{u}$ otros dispositivos para incontinencia de esfuerzo de distintos gra$\operatorname{dos}^{1,24,56,60}$, aunque esta tasa puede llegar al $27 \%{ }^{86}$. En los pacientes no irradiados, la utilización de inyecciones periuretrales o el esfinter artificial pueden ser la solución definitiva.

El esfacelamiento uretral originado por la crionecrosis tisular ha disminuido notablemente con la utilización de los calentadores uretrales, descendiendo su incidencia desde el $85 \%$ que acontecía cuando no se empleaban dichos calentadores $^{40}$, hasta las cifras actuales del 3,8-23\% con el empleo de los mismos ${ }^{24,59,71,86}$,pudiendo desencadenar este fenómeno una obstrucción urinaria. También, a consecuencia de la destrucción de la mucosa uretral, el tejido necrótico prostático en contacto directo con la orina es más susceptible a la infección, hecho que se produce en un $0-6,3 \%$ de $\operatorname{casos}^{59,71}$; siendo esta infección además, muy resistente a la antibioterapia sistémica. La obstrucción infravesical derivada de presencia de este tejido necrótico puede precisar de la práctica de una resección transuretral desobstructiva, situación que alcanza una incidencia de un 5,5-18\%1,56,86. La estenosis de cuello vesical y uretra, aunque es excepcional, también puede acontecer como consecuencia de un esfacelamiento tisular masivo ${ }^{43}$.

Entre un $0,4 \%$ y un $11 \%$ de los pacientes tratados primariamente con criocirugia, presentan dolor perineal (pélvico y rectal) ${ }^{24,39,86}$, de etiología no bien conocida, si bien parece multifactorial (isquemia pared rectal, extravasación de orina al tejido periprostático, etc.).

La lesión del nervio dorsal del pene se manifiesta mediante parestesias en pene, fenómeno que está descrito en un $10 \%$ de pacientes $^{24}$. Generalmente es una situación transitoria que se resuelve espontáneamente.

Tabla 7 $\mathrm{ND}=$ No especificado
Las complicaciones se presentan con mayor incidencia en los pacientes sometidos a criocirugía de rescate postirradiación. En el caso de criocirugía de rescate, si se utiliza una estricta definición de incontinencia como es la percepción del paciente sobre el control vesical, alrededor de un $70-80 \%$ de pacientes refieren algún grado de incontinencia ${ }^{47,60}$. La incontinencia puede mejorar pasados los primeros meses, especialmente si se utilizan calentadores uretrales y situarse en tasas del $47 \%$ pasado el primer año ${ }^{87}$. El esfacelmiento uretral puede acontecer en un $44 \%$ de pacientes ${ }^{47}$. El dolor perineal ocurre entre un 21$77 \%{ }^{47,77}$. La fístula rectouretral, suele acontecer entre el $0-3 \%{ }^{47,76,77,79}$, aunque en alguna serie alcanza el 11\%60 (Tabla 7).

\section{TRATAMIENTO DE LA RECAÍDA LOCAL POSTCRIOCIRUGÍA}

Como se comentó anteriormente, una de las ventajas de la CRA es que el procedimiento puede ser repetido más de una vez sin aumentar el riesgo de complicaciones. Por ello, la propia crioablación constituye el tratamiento de la recurrencia local en la mayoría de los casos.

La prostatectomía radical también ha sido utilizada como tratamiento de la recurrencia postcriocirugía. Cuando la crioterapia es completa, suele existir una importante reacción fibrosa pericapsular que puede dificultar enormemente la exéresis. Sin embargo, la radioterapia constituye una alternativa más segura, especialmente en los pacientes de riesgo intermedio o alto, para tratar una posible extensión extraprostática del tumor $^{43}$.

Complicaciones de la criocirugía prostática de rescate (\%)

\begin{tabular}{|c|c|c|c|c|c|c|}
\hline & $\mathbf{D E}$ & $\mathbf{I U}$ & E. Uretra & Obstrucción & Dolor & Fistula U-R \\
\hline Han et al. ${ }^{41}$ & ND & 9 & 0 & 3 & ND & 0 \\
\hline Pisters et al. ${ }^{47}$ & 72 & 73 & 44 & 67 & ND & 1 \\
\hline Long et al. ${ }^{60}$ & ND & 80 & ND & ND & ND & 11 \\
\hline Ghafar et al. ${ }^{76}$ & 47 & 3 & 9 & 5 & 1 & 1 \\
\hline Chin et al. ${ }^{79}$ & ND & 6,7 & 5 & 8,5 & ND & 3,3 \\
\hline
\end{tabular}

$\mathrm{DE}=$ Disfunción erectil; IU= Incontinencia; E. Uretra= Esfacelamiento; Fístula U-R= Uretro-rectal; 


\section{CONSIDERACIONES FINALES}

Existen algunas ventajas, evidentes, que pueden aconsejar el empleo de la criocirugía en el tratamiento del cáncer de próstata localizado: procedimiento mínimamente invasivo, exento de los efectos derivados de la radiación, capacidad para eliminar poblaciones celulares andrógenoindependientes, posibilidad de tratamiento de enfermedad extracapsular, escasa pérdida hemática, corta estancia hospitalaria, posibilidad de realizarlo con anestesia local. Además, presenta un coste económico notablemente inferior al que suponen la prostatectomía o la radioterapia ${ }^{46,54}$.

No obstante, la ausencia de estudios prospectivos y multicéntricos diseñados para establecer la verdadera eficacia de los resultados de esta técnica y compararlos con los obtenidos con la cirugía o la radioterapia, no nos permite considerar todavía a la CRA como una alternativa real a los tratamientos actualmente establecidos como electivos en el carcinoma de próstata localizado. Además, la posibilidad de desarrollo de ciertas complicaciones, especialmente una tasa extraordinariamente elevada de impotencia, son factores que se deben valorar a la hora de ofrecer esta modalidad terapéutica al paciente.

Nuevos planteamientos terapéuticos como la posibilidad de combinar la criocirugía con algunos quimioterápicos como el 5-fluoruracilo (quimiocriocirugía) ${ }^{88}$, modificadores de respuesta biológica ${ }^{89}$, o algunas "proteínas anticongelantes" 90 pueden suponer una mejoría de los resultados oncológicos de la crioablación y un mayor control de los efectos adversos y hacer entonces de esta modalidad terapéutica una opción competitiva para el tratamiento del cáncer prostático localizado.

\section{REFERENCIAS}

1. Bahn DK, Lee F, Badalament R, Kumar A, Greski J, Chernick M. Targeted cryoablation of the prostate: 7-year outcomes in the primary treatment of prostate cancer. Urology. 2002; 60(suppl 2A):3-11.

2. Soanes WA, Gonder MJ, Shulman S. Apparatus and technique for cryosurgery of the prostate. J Urol. 1966;96:508511.

3. Flocks RH, Nelson CM, Boatman DL. Perineal cryosurgery for prostatic carcinoma. J Urol. 1972;108:933-935.

4. Porter MP, Ahaghotu CA, Loening SA, See WA. Disease-free and overall survival after cryosurgical monotherapy for clinical stages B and C carcinoma of the prostate: A 20-year followup. J Urol. 1997;158:1466-1469.
5. Onik GM, Cohen JK, ReyesGD, Rubinsky B, Chang Z, Baust J. Transrectal ultrasound-guided percutaneous radical cryosurgical ablation of the prostate. Cancer. 1993;72:1291-1299.

6. Saliken JC, Donnelly BJ, Rewcastle JC. The evolution and state of modern technology for prostate cryosurgery. Urology. 2002;62(suppl 2A):26-33.

7. Ellis DS. Criosurgery as primary treatment for lacalized prostate cancer: A community hospital experience. Urology. 2002;60(suppl 2A):34-39.

8. Gage AA, Baust J. Mechanisms of tissue injury in cryosurgery. Cryobiology. 1998;37:171.

9. Mazur P. Cryobiology: The freezing of biological systems. Science. 1970;168:939-949.

10. Hoffmann NE, Bischof JC. The cryobiology of cryosurgical injury. Urology. 2002;60(Suppl 1):40-49.

11. Whitaker DK. Mechanism of tissue destruction following cryosurgery. Am R Coll Surg England. 1984;66:313-318.

12. Zook N, Hussman J, Brown R, Russell R, Kucan J, Roth A, et al. Microcirculatory studies of frosbite injury. Ann Plast Surg. 1998;40:246-253.

13. Hollister WR, Mathew AJ, Baust JG, van Buskirk RG: The effects of freezing on cell viability and mechanism of cell death in an in vitro human prostate cancer cell line. Mol Urol. 1998;2:13-18.

14. Dachs GU, Stratford IJ. The molecular response of mammalian cells to hypoxia and the potential for exploitation in cancer therapy. Br J Cancer. 1996;Suppl 27: S126-132

15. Baust JG, Gage AA. The molecular basis of cryosurgery. BJU International 2005, 95:1187-1191.

16. Mazur P. Freezing of living cells: Mechanism and implications. Am J Phisyol. 1984;143:125-142.

17. Tatsutani K, Rubinsky B, Onik G, Dahiya R. Effect of thermal variables on frozen human primary prostatic adenocarcinoma cells. Urology. 1996;48:441-447.

18. Bischof JC, Cristov K, Rubinsky BA: A morphological study of the cooling rate response of normal and neoplastic human liver tissue: Criosurgical implications. Cryobiology. 1993;30:482-492.

19. Hong J, Rubinsky B. Patterns of ice formation in normal and malignant breast tissue. Cryobiolgy. 1994, 31:109120.

20. Keanini GR, Rubinsky B. Optimization of multiprobe cryosurgery. J Heat Trans. 1992;114:796-802.

21. Yang WH, Peng HH, Chang HC, Shen Y, Wu CL, Chang $\mathrm{CH}$. An in vitro monitoring system for simulated thermal process in cryosurgery. Cryobiology. 2000;40:159-170.

22. Uchida M, Imaide I, Sugimoto K. Uehara H, Watanabe H: Percutaneous cryosurgery for renal tumors. Br J Urol. 1995;75:132-137.

23. Smith DJ, Fahssi WM, Swanlund DJ, Bischof JC. A parametric study of freezing injury in AT-1 rat prostate tumor cells. Cryobiology. 1999;39:13-28.

24. Shinohara K, Connolly JA, Presti JC. Jr, Carroll PR: Cryosurgical treatment of localized prostate cancer (Stages T1 to T4): Preliminary results. J Urol. 1996;156:115-120.

25. Dilley AV, Dy D, Walters A, Copeland S, Gilles AE, Morris RW, et al: Laboratory and animal model evaluation of Criotech LCS 2000 in hepatic cryosurgery. Cryobiology. 1993;30:74-85.

26. Patel BG, Parsons CL, Bidair M, Schmidt JD. Cryoablation for carcinoma of the prostate. J Surg Oncol. 1996;63:256264. 
27. Connolly JA, Shinohara K, Presti JC, Carroll PR. Should cryosurgery be considered a therapeutic option in localized prostate cancer? Urol Clin North Am. 1996;23:623-631.

28. Larson TR, Robertson DW, Corica A, Bostwick DG. In vivo interstitial temperature mapping of the human prostate during cryosurgery with correlation to histopathologic outcomes. Urology. 2000;55:547-552.

29. Pisters LL, Dinney CPN, Pettaway CA, Scott SM, Babaian RJ, von Eschenbach AC, et al: A feasibility study of cryotherapy followed by radical prostatectomy for locally advanced prostate cancer. J Urol. 1999;161:509-514.

30. Sandison GA. Future directions for cryosurgery computer treatment planning. Urology. 2002;60(suppl 2A):50-55.

31. Lee F, Bahn DK, McHugh TA, Onik GM, Lee FT. Jr. Technique of US-guided percutaneous cryoablation of prostate cancer. Radiology. 1994;192:769-776.

32. Baust J, Gage AA, Ma H, Zhang C. Minimally invasive cryosurgery-technologycal advances. Cryobilogy. 1997;34:373-384.

33. Rewcastle JC, Sandison GA, Saliken JC, Donnelly BJ, McKinnon JG. Considerations during clinical operation of two commercially available cryomachines. J Surg Oncol. 1999;71:106-111.

34. Han K, CohenJK, Miller RJ, Pantuck AJ, Freitas DG, Cuevas CA, et al. Treatment of organ confined prostate cancer with third generation cryosurgery: preliminary multicenter experience. J Urol. 2003;170: 1126-1130.

35. Chin JL, Downey DB, Mulligan M, Fenster A: Three-dimensional transrectal ultrasound guided cryoablation for localized prostate cancer in nonsurgical candidates: a feasibility study and report of early results. J Urol. 1998; 159:910-914.

36. Saliken JC, McKinnon JG, Gray R. CT for monitoring cryotherapy. AJR Am J Roentgenol. 1996;166:853-855.

37. Mala T, Samset E, Aurdal I, Gladhaug I, Edwin B, Soreide O. Magnetic resonance imaging-estimated three-dimensional temperature distribution in liver cryolesions. A study of cryolesion characteristics assumed necessary for tumor ablation. Cryobiology. 2001;43:268-275.

38. Daniel BL, ButtsK, Block WF. Magnetic resonance imaging of frozen tissues: temperature-dependent MR signal characteristics and relevance for MR monitoring cryosurgery. Magn Reson Med. 1999;41:627-630.

39. Cohen J, Miller RJ, Shuman BA. Urethral warming catheter for use during cryoablation of the prostate. Urology. $1995,45: 861-864$

40. Wong WS, Chinn DO, Chinn M, Tom WL, Tom W. Cryosurgery as a treatment for prostate carcinoma: results and complications. Cancer. 1997;79: 963-974.

41. Han KR, Belldegrun AS. Third-generation cryosurgery for primary and recurrent prostate cancer. BJU 2004;93:14-18.

42. Rabin Y, Lung DC, Stahovich TF. Computerized planning of cryosurgery using cryoprobes and cryoheaters. Technol Cancer Res Treat. 2004;3:229-243.

43. Shinohara K. Prostate cancer: cryotherapy. Urol Clin N Am. 2003;30:725-736.

44. Ahmed S, Lindsey B, Davies J. Salvage cryosurgery for locally recurrent prostate cancer following radiotherapy. Prostate Cancer and Prostatic Diseases. 2005;8:31-35.

45. Da la Taille A, Katz AE. Cryosurgery: is it an effective option for patients failing radiation? Curr Opin Urol. 2000;10:409-413.

46. Schmidt JD, Doyle J, Larison S: Prostate Cryoablation: Update 1998. CA Cancer J Clin. 1998;48:239-253.
47. Pisters LL, von Eschenbach AC, Scott SM, Shellie M, Swanson DA, Dinney CP, et al. The efficacy and complications of salvage cryotherapy of the prostate. J Urol. 1997; 157:921-925.

48. Cohen JK. Cryosurgery of the Prostate: Techniques and Indications. Rev Urol. 2004;6(suppl 4):S20-S26.

49. Onik G, Narayan P, Vaughan D, Dineen M, Brunelle R. Focal 'nerve-sparing' cryosurgery for treatment of primary prostate cancer: a new approach to preserving potency. Urology. 2002;60:109-114.

50. Katz AE, Rewcastle JC. The current and potential role of cryoablation as a primary therapy for localized prostate cancer Curr Oncol Rep. 2003;5:231-238.

51. Rees J, Patel B, Macdonagh R, Persad R. Cryosurgery for prostate cancer. BJU 2004;93:710-714

52. Prepelica KL, Okeke Z, Murphy A, Katz AE. Cryosurgical Ablation of the Prostate: High-Risk Patient Outcomes. Cancer. 2005; 103:1625-1630.

53. Koppie TM, Shinohara K, Grossfeld GD, Presti JC, Carroll PC. The efficacy of cryosurgical ablation of prostate cancer: the University of California San Francisco experience. J Urol. 1999; 162:427-432.

54. Pisters LL, Perrotte P, Scott SM, Greene GF, von Eschenbach AC. Patient selection for salvage cryotherapy for locally recurrent prostate cancer after radiation therapy. J Clin Oncol. 1999; 17:2514-2520.

55. Merrick GS, Wallner KE, Butler WM. Prostate cryotherapy: more questions than answers Urology. 2005;66:9-15.

56. Long JP, Bahn D, Lee F, Shinohara K, Chinn DO, Macaluso JNJr. Five year retrospective multi-institutional pooled analysis of cancer-related outcomes after cryosurgical ablation of the prostate. Urology. 2001;57:518-523.

57. Escudero Barrilero A, Arias Funes F, Rodríguez Patrón Rodríguez R, García González R. Criocirugía (tercera parte). revisión de la literatura y nuestra experiencia. (II). Arch Esp Urol 2005;58:1003-1029.

58. Aus G, Pileblad E, Hugosson J. Cryosurgical ablation of the prostate: 5-year follow-up of a prospective study. Eur Urol. 2002;42:133-138.

59. Weider J, Schmidt JD, Casola G, Van Sonnenberg E, Stainken BF, Parsons CL. Transrectal ultrasound-guided transperineal cryoablation in the treatment of prostate carcinoma: Preliminary results. J Urol. 1995; 154:435-441.

60. Long JP, Fallick ML, LaRock DR, Rand W. Preliminary outcomes following cryosurgical ablation of the prostate in patients with clinically localized prostate carcinoma. J Urol. 1998;159:477-484.

61. Bahn DK, Lee F, Solomon MH, Gontina H, Klionsky DL, Lee FT Jr. Prostate cancer: US-guided percutaneous cyoablation. Radiology. 1995; 194:551-556.

62. Shinohara K, Rhee B, Presti JC. Jr, Carroll PR. Cryosurgical ablation of prostate cancer: patterns of cancer recurrence. J Urol. 1997;158:2206-2209.

63. Leibovich BC, Blute ML, Bostwick DG, Wilson TM, Pisansky TM, Davis BJ, et al. Proximity of prostate cancer to the urethra: implications for minimally invasive ablative therapies. Urology. 2000;56:726-729.

64. Saliken JC, Donnelly BJ, Brasher P, Ali-Ridha N, Ernst S, Robinson J. Outcome and Safety of Transrectal US-guided Percutaneous Cryotherapy for Localized Prostate Cancer. J. Vasc Interv Radiol. 1999;10:199-208.

65. Cohen JK, Miller RJ, Rooker GM, Shuman BA. Cryosurgical ablation of the prostate: Two-year prostate-specific antigen and biopsy results. Urology.1996;47:395-401. 
66. Shuman BA, Cohen JK, Miller RJ Jr, Rooker GM, Olson PR. Histological presence of viable prostatic glands on routine biopsy following cryosurgical ablation of the prostate. J Urol. 1997;157:552-555.

67. Grampsas SA, Miller GJ, Crawford ED. Salvage radical prostatectomy after failed transperineal cryotherapy: histologic findings from prostate whole-mount specimens correlated with intraoperative transrectal ultrasound images. Urology. 1995;45:936-941.

68. Escudero Barrilero A, Arias Funes F, Rodríguez Patrón Rodríguez R, García González R, Cuesta Roca C. Criobiología y lesiones anatomopatológicas inducidas por la congelación-deshielo en el tejido prostático. $2^{\underline{a}}$ parte. Arch Esp Urol. 2004;57:1073-1090.

69. Littrup PJ, Mody A, Sparschu R, Prchevski P, Montie J, Zingas AP, et al: Prostatic cryotherapy: Ultrasonographic and pathologic correlation in the canine model. Urology. 1994;44:175-183.

70. Leibovici D, Zisman A, Lindner A, Stav K, Siegel YI. PSA elevation during prostate cryosurgery and subsequent decline. Urol Oncol. 2005;23:8-11.

71. Coogan CL, McKiel CF. Percutaneous Cryoablation of the Prostate: Preliminary Results After 95 Procedures. J Urol. 1995;154:1813-1817.

72. Donnelly BJ, Saliken JC, Ernst DS, Ali-Ridha N, Brasher PMA, Robinson JW, et al. A prospective trial of cryosurgical ablation of the prostate: Five-year results. Urology. 2002;60:645-649.

73. Gould RS. Total cryosurgery of the prostate versus standard cryosurgery versus radical prostatectomy: comparison of early results and the role of transurethral resection in cryosurgery. J Urol. 1999;162:1653-1657.

74. Touma NJ, Izawa JI, Chin JL. Current status of local salvage therapies following radiation failure for prostate cancer. J Urol. 2005; 173:373-379.

75. Greene GF, Pisters LL, Scott SM, von Eschenbach AC Predictive value of prostate specific antigen nadir after salvage cryotherapy. J Urol. 1998;160:86-90.

76. Ghafar MA, Johnson CW, de la Taille A, Benson MC Bagiella E, Fatal M, et al. Salvage cryotherapy using an argon based system for locally recurrent prostate cancer after radiation therapy: the Columbia experience. J Urol. 2001;166:1333-1338.

77. Bales GT, Willians MJ, Sinner M, Thisted RA, Chodak GW. Short-term outcomes after cryosurgical ablation of the prostate in men with recurrent prostate carcinoma following radiation failure. Urology. 1995;46:676-680.

78. Izawa JI, Madsen LT, Scott SM, Tran JP, McGuire EJ, von Eschenbach AC, et al. Salvage cryotherapy for recurrent prostate cancer after radiotherapy: variables affecting patient outcome. J Clin Oncol. 2002;20: 2664-2671.
79. Chin JL, Pautler SE, Mouraviev V, Touma N, Moore K, Downey DB. Results of salvage cryoablation of the prostate after radiation: identifying predictors of treatment failure and complications. J Urol. 2001;165:1937-1942.

80. Chin JL, Touma N, Pautler SE, Guram KS, Bella AJ, Downey DB et al. Serial histopathology results of salvage cryoablation for prostate cancer after radiation failure. $\mathrm{J}$ Urol. 2003; 170:1199-1202.

81. Bahn DK, Lee F, Silverman P, Bahn E, Badalament R, Kumar A, et al. Salvage cryosurgery for recurrent prostate cancer after radiation therapy: a seven-year follow-up. Clin Prostate Cancer. 2003;2:111-114.

82. Rukstalis DB, GoldknoffJL, Crowley EM, Garcia FU. Prostate cryoablation: A scientific rationale for future modifications. Urology. 2002;60(suppl 2A):19-25.

83. Janzen NK, Han KR, Perry KT, Said JW, Schulam PG, Belldegrun AS. Feasibility of nerve-sparing prostate cryosurgery: applications and limitations in a canine model. J Endourol. 2005; 19:520-525.

84. Robinson JW Donnelly BJ Saliken JC Weber BA, Ernst S, Rewcastle JC. Quality of life and sexuality of men with prostate cancer 3 years after cryosurgery. Urology. 2002; 60(Suppl 2a ): 12-18.

85. Green TC. Avances en crioterapia 2004. Criobiologia. Arch Esp Urol. 2005;58:589-596.

86. Cox RL, Crawford ED. Complications of cryosurgical ablation of the prostate to treat localized adenocarcinoma of the prostate. Urology. 1995;45:932-935.

87. Perrotte P, Litwin MS, McGuire EJ, Scott SM, von Eschenbach AC, Pisters LL. Quality of life after salvage cryotherapy: the impact of treatment parameters. J. Urol. 1999;162:398-402.

88. Clarke DM, Baust JM, Van Buskirk RG. Chemo-cryo combination therapy: an adjunctive model for the treatment of prostate cancer. Cryobiology. 2001;42:274-285.

89. Chao $\mathrm{BH}, \mathrm{He} \mathrm{X}$, Bischof JC. Pre-treatment inflammation induced by TNF-alpha augments cryosurgical injury on human prostate cancer. Cryobiology. 2004;49:10-27.

90. Pham L, Dahiya R, Rubinsky B: An in vivo study of antifreeze protein adjuvant cryosurgery. Cryobiology. 1999;38: 169-175.

Correspondencia autor: J.L Pontones Moreno

Servicio de Urología Hospital Universitario La Fe Avda. Campanar 21, 46009 Valencia. Tel.: 963862700

E-mail autor: pontones_jos@gva.es

Información artículo: Revisión - Cáncer de próstata

Trabajo recibido: noviembre 2006

Trabajo aceptado: diciembre 2006 